Document downloaded from:

http://hdl.handle.net/10251/84336

This paper must be cited as:

Zeballos, JL.; Adibi, W.; Giménez Millán, R.; Monforte Gilabert, AJ.; Moreno, MA.; Gogorcena, Y. (2016). Mapping QTLs associated with fruit quality traits in peach Prunus persica (L.) Batsch using SNP maps. Tree Genetics and Genomes. 12(3):1-17. doi:10.1007/s11295-016-0996-9.

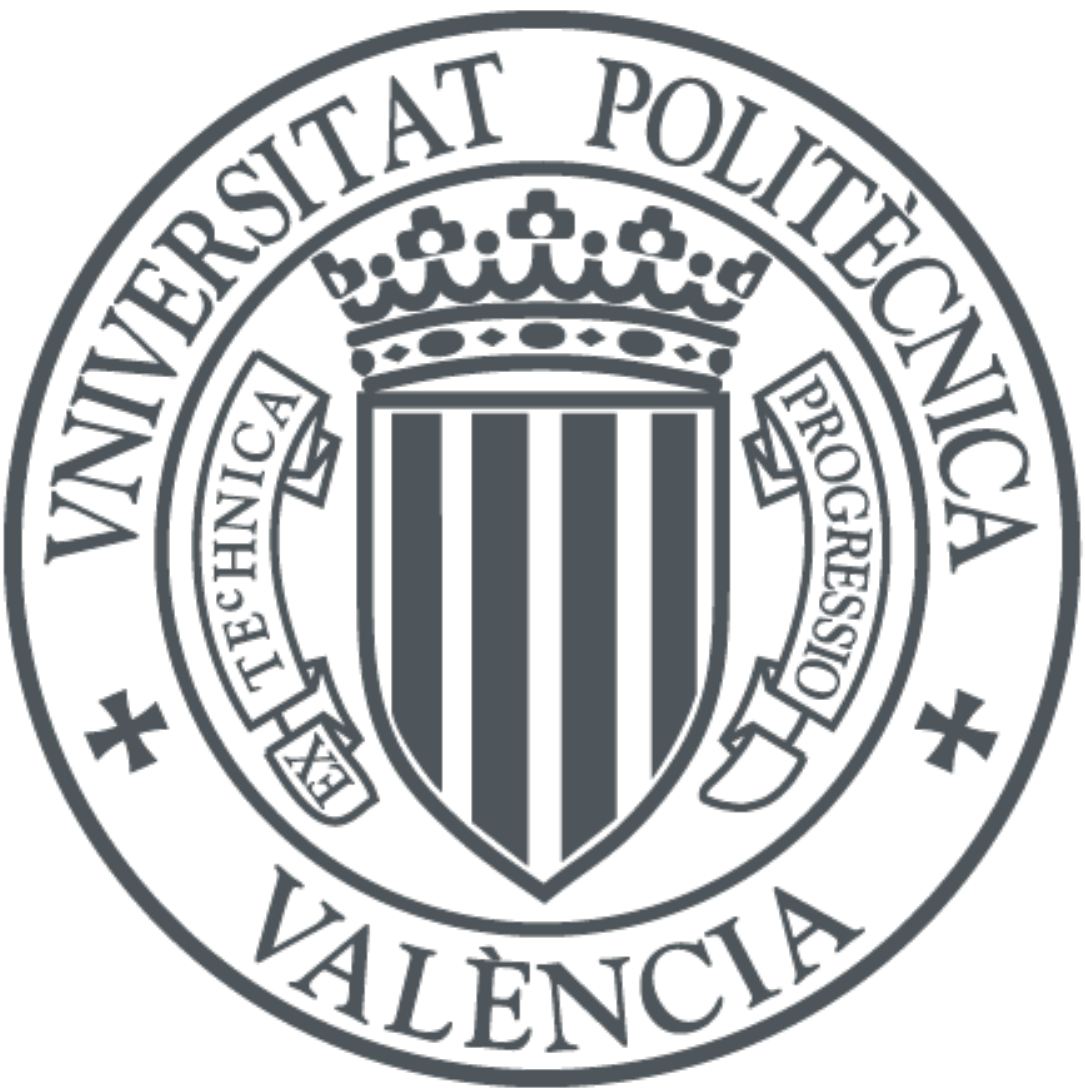

The final publication is available at

http://doi.org/10.1007/s11295-016-0996-9

Copyright Springer Verlag (Germany)

Additional Information 


\section{Mapping QTLs associated with fruit quality traits in peach [Prunus persica (L.) Batsch] using SNP maps}

José Luis Zeballos $^{1 *}$, Walid Abidi ${ }^{1 *}$, Rosa Giménez ${ }^{1}$, Antonio J Monforte ${ }^{2}$, María

$\underline{\text { Ángeles Moreno }}^{1}, \underline{\text { Yolanda Gogorcena }}^{1+}$

"These authors contributed equally to develop this research.

${ }^{1}$ Estación Experimental de Aula Dei-CSIC, Department of Pomology, P.O. Box 13034,

50080 Zaragoza, Spain

†: corresponding author, phone: +3497671 6133, fax: +34 97671 6145, e-mail: aoiz@eead.csic.es

${ }^{2}$ Instituto de Biología Molecular y Celular de Plantas-(CSIC-UPV), 46022 Valencia, Spain

\section{Abstract}

Fruit quality is an essential criterion used to select new cultivars in peach breeding programs and is determined based on a combination of organoleptic and nutritional traits. The aim of this study was to identify quantitative trait loci (QTLs) for fruit quality traits in an $F_{1}$ nectarine population derived from 'Venus' and 'Big Top' cultivars. The progeny were evaluated over 4 years for agronomical and biochemical characteristics, and genotyped using SSR markers and 'IPSC 9K peach SNP array v1'. Two genetic maps were constructed using 411 markers. The 'Venus' map spanned $259 \mathrm{cM}$ on nine linkage groups (LGs) with 104 markers. The 'Big Top' map spanned 464 cM on ten LGs with 122 markers. Single or Multiple QTL models mapping was applied separately for each year and all years combined. A total of 54 QTLs mapped over 12 LGs belonged to seven peach chromosomes. Most of the QTLs were consistent over the 4 years of study and were validated with the Multi-year analysis. QTLs for total phenolic, flavonoid, and anthocyanin contents were reported for the first time in peach. LG4 in 'Venus' and LG5 in 'Big Top' showed the highest numbers of QTLs. This work represents the first study in an $\mathrm{F}_{1}$ nectarine family to identify peach genomic regions that control fruit quality traits using 'IPSC 9K SNP array v1' and provides useful information for marker-assisted breeding to produce peaches with better antioxidant content and healthy attributes.

Key words: peach physical map, vitamin C, total phenolics, flavonoids, anthocyanins, sugars 


\section{Introduction}

Peach [Prunus persica (L.) Batsch] is the third most important fruit crop worldwide in terms of production (FAOSTAT 2015). In Spain, the first peach exporter to Europe, peach is an economically important crop; it covers a large area (84,400 ha in 2013), being the second in peach production in the European Union and third worldwide (FAOSTAT 2015).

Fruit quality is important for the peach industry because it can modify consumer preference. Traits such as flesh texture, color, sweetness, acidity, and other organoleptic attributes may affect consumption of specific varieties (Crisosto 2002). In recent years, consumers have attached greater importance to functional foods, which have healthpromoting properties, such as antioxidant, antimutagenic, and anticarcinogenic effects (Orazem et al. 2011; Vizzotto et al. 2014). In conjunction these traits represent food quality, which has become a primary goal in many international peach breeding programs in recent decades (Infante et al. 2008; Cantín et al. 2009a; Byrne et al. 2012). Unfortunately, most traits related to fruit quality are quantitatively inherited and the genetic control of many of these traits is still unknown (Eduardo et al. 2011).

Determining the genetic basis of these traits is necessary to understand their genetic control and will provide necessary information to develop specific approaches to enhance breeding programs (Peace and Norelli 2009).

Peach is one of the best characterized fruit tree species which, due to its short juvenility period and the simplicity of its genome, serves as a model for genetic studies in Rosaceae (Zeballos 2012 and references therein). Moreover, the availability of the $\mathrm{T} \times$ E Prunus reference map (Dirlewanger et al. 2004), the release of the peach genome v1.0 and v2.0 (Arús et al. 2012; Verde et al. 2013), and the recent development of single nucleotide polymorphism (SNP) genotyping platforms offer the opportunity to determine the inheritance of many qualitative and quantitative traits at the molecular level (Frett et al. 2014). Likewise, alignment of the updated physical map to the Prunus reference map would provide the Prunus research community with a basis for comparing the positions of the major genes and quantitative trait loci (QTLs) identified in several previous studies across different mapping populations.

However, as mentioned above, many agricultural traits are quantitative in nature, and determining their genetic basis is complicated because the majority of genes have little 
effect and few have substantial effects (Brem and Kruglyak 2005). Many studies have been carried out for QTL identification in Prunus (Zeballos 2012). Nevertheless, many important agronomic traits of Prunus species have not yet been mapped, and only a few are currently being used for marker-assisted selection (including major genes for disease and pest resistance, self-incompatibility, slow ripening, and fruit quality traits such as flesh color, endocarp staining, flesh adherence to stone, non-acid fruit, skin pubescence, skin color, and fruit shape) (Dirlewanger et al. 2004; Eduardo et al. 2015; Ru et al. 2015 and references therein). Important QTLs that control fruit quality traits have been found for total sugar content, organic acid content, fruit weight, acidity, blooming and harvest dates (Dirlewanger et al. 1999; Etienne et al. 2002; Quilot et al. 2004), blooming and ripening dates (Eduardo et al. 2011; Dirlewanger et al. 2012), chilling injury susceptibility (Cantín et al. 2010a), and other traits anchored in the T $\times$ E Prunus reference map that have been widely described by Arús et al. (2012). Most previous studies have been limited because of the low marker density in the maps (Eduardo et al. 2013). However, the availability of SNP genotyping resources has assisted in fine mapping of peach (Martínez-García et al. 2013a,b; Zhebentyayeva et al. 2014). More recently, attempts have been made to map QTLs in peach using the newly developed SNP genotyping array v1 (Verde et al. 2012). Several QTLs that control traits such as chilling and heat requirements (Romeu et al. 2014), blush (Frett et al. 2014), maturity date (Pirona et al. 2013; Fresnedo-Ramírez et al. 2015; Nuñez-Lillo et al. 2015) or other pomological traits such as fruit weight, soluble solids content or $\mathrm{pH}$ (Fresnedo-Ramírez et al. 2015) have been mapped. Moreover, the current analytical techniques are more powerful for large-scale phenotyping than older methods, and new traits related to fruit quality are being incorporated in QTL analysis. For example, aroma and other volatile compounds were partially mapped onto the Prunus reference map (Illa et al. 2011; Eduardo et al. 2013) and were analyzed using a high-throughput gas chromatography-mass spectrometry (GC-MS)-based metabolomics approach (Sánchez et al. 2012). Some phenolic compounds (pigments) were mapped on the $\mathrm{T} \times \mathrm{E}$ reference map (Ogundiwin et al. 2009), and other phenolic compounds (Chagné et al. 2012; Verdu et al. 2014) and vitamin C (Davey et al. 2006) were identified in apple, but to our knowledge no QTLs that control phenolic compounds (including total phenolic, flavonoid, or anthocyanin contents) or vitamin $\mathrm{C}$ have been mapped in peach. These antioxidant compounds are important and potentially beneficial to human health 
because they are involved in the prevention of degenerative diseases such as hypertension, coronary heart diseases, Alzheimer's disease, stroke, and cancer (Boeing et al. 2012; Martin et al. 2013; Vizzotto et al. 2014).

To our knowledge, there is no peach breeding program that enhances antioxidant contents, despite the importance of healthy nutraceutical compounds from peach and other fruits (Wargovich et al. 2012). The peach breeding program at the Experimental Station of Aula Dei-CSIC has studied, over a period of 10 years, a nectarine population derived from a cross between 'Venus' and 'Big Top' cultivars. This progeny have been phenotyped for agronomic and fruit quality attributes over a period of 4 years. Moreover, this population has been genotyped with simple-sequence repeats (SSRs) and 'IPSC 9K peach SNP array v1' markers.

The main objective of this study was to identify genetic regions associated with the most important peach pomological traits using the 'Venus' $\times$ 'Big Top' mapping population. To achieve this goal, two genetic maps were constructed with IPSC 9K peach SNP array v1 and six SSR markers, and the obtained maps were previously compared with the peach physical map and anchored to the Prunus reference map T $\times$ E. A QTL analysis was performed using the maps and the phenotypic data obtained during the 4 years of evaluation (2007-2010). In this paper, we describe the identification of genomic regions that regulate the main fruit quality traits in peach using IPSC 9K peach SNP array v1. Quantitative trait loci for total phenolic, flavonoid, and anthocyanin contents are reported for the first time in this species.

\section{Material and Methods}

\section{Plant material}

The mapping population included 75 offspring of $F_{1}$ progeny from a cross between two diploid outbreed nectarine cultivars, with 'Venus' as the female parent and 'Big Top' as the male parent. Both cultivars are nectarines with red skin and yellow flesh. 'Venus' is freestone and acidic, whereas 'Big Top' is clingstone and sub-acidic. The progeny were established in the Aula Dei Experimental Station orchards in 2002 as described by Cantín et al. (2009b). One tree per genotype was grafted on GF 677 and grown under standard irrigation, fertilization, and pest control conditions. Winter pruning and spring thinning were conducted as in commercial orchards. 


\section{Agronomical and pomological evaluation}

Over a period of 4 years (2007-2010), agronomic and pomological traits were measured in each seedling tree. Production (yield), fruit weight, flesh firmness, soluble solids concentration (SSC), pH, titratable acidity (TA) were evaluated for 3 years $(2007,2009$ and 2010); relative antioxidant capacity (RAC), and contents of vitamin C, total phenolic, flavonoids, anthocyanins, and individual sugars were evaluated for 4 years as previously reported (Cantín et al. 2009b; 2010b; Abidi et al. 2011; 2015). For production, all fruits from each tree were harvested and weighed $(\mathrm{Kg} /$ tree $)$. Then, a subsample of 20 fruits/tree was weighed to calculate the average fruit weight, which was used for subsequent analysis. Flesh firmness was measured in 10 fruits with a hand penetrometer. Five fruits were homogenized in a blender to determine SSC of juice with a temperature-compensated refractometer (model ATC-1, Atago Co., Tokyo, Japan), and $\mathrm{pH}$ and TA were measured with an automatic titration system (862 Compact Titrosampler, Metrohm, Herisau, Switzerland). Ripening index (RI) was calculated as the ratio of SSC to TA. For biochemical analyses, five arbitrarily selected fruits were peeled and cut in small cubes $\left(\sim 1 \mathrm{~cm}^{3}\right)$ to pool homogeneous sub-samples of $5 \mathrm{~g}$-flesh, immediately frozen in liquid nitrogen and then stored at $-20{ }^{\circ} \mathrm{C}$ until analysis. To preserve ascorbic acid, sub-samples were frozen with $5 \mathrm{~mL}$ of meta-phosphoric acid $(5 \%)$ in liquid nitrogen and then stored at $-20^{\circ} \mathrm{C}$. Then, samples were homogenized in a polytron for $2 \mathrm{~min}$ with $10 \mathrm{~mL}$ of extraction solution of $0.5 \mathrm{~mol} \mathrm{~L}^{-1} \mathrm{HCl}$ in $800 \mathrm{~mL}$ $\mathrm{L}^{-1}$ methanol for phenolic content, $800 \mathrm{~mL} \mathrm{~L}^{-1}$ ethanol for sugar content, and $50 \mathrm{~mL} \mathrm{~L}^{-1}$ metaphosphoric for vitamin $\mathrm{C}$ and processed as previously described (Cantín et al. 2009b; Abidi et al. 2011). Vitamin C, total phenolic, flavonoid, and anthocyanin contents, and RAC were evaluated with colorimetric methods and measured using a spectrophotometer (Beckman Coulter DU 800, Beckman Coulter, Brea, CA, USA) as previously described (Abidi et al. 2011; 2015). For the sugar profile, sugar composition and quantification were analyzed by high-performance liquid chromatography as described by Cantín et al. (2009a) with some modifications as described in Abidi et al. (2011).

\section{Statistical analysis}

Descriptive statistics of all phenotypic data were calculated using SPSS $® 22.0$ (IBM®). Data were averaged and minimum and maximum values were identified. To evaluate 
whether the data followed a normal distribution, a normality analysis by KolmogorovSmirnov and Shapiro-Wilk test was performed separately each year/trait. Histograms for each trait were constructed with all data set. Pearson's correlation coefficients among years were calculated for 2007, 2008, 2009 and 2010. The number of records, varied from year to year. Correlations among variables were performed with the mean value for all years. Since correlations between years for most of the traits were low or moderate, QTL analysis was carried out separately for each year. The Box-Cox transformation method was used for non-normally distributed traits to perform multiple QTL model (MQM)-QTL analysis.

\section{Population genotyping and marker selection}

For genotyping, total DNA was extracted from the young leaves of both parents, 'Venus' and 'Big Top', and each progeny using the DNeasy® Plant Mini Kit (QIAGEN Inc., Valencia, CA, USA) following the manufacturer's instructions. DNA concentration and quality was checked using PicoGreen ${ }^{\circledR}$ dye and measured in a fluorospectrometer. Then, all samples were genotyped using IPSC 9K peach SNP array v1, which includes 8,144 SNP markers (Verde et al. 2012), using the single-base extension assay (Steemers et al. 2006) and Illumina ${ }^{\circledR}$ Infinium ${ }^{\circledR}$ HD Assay Ultra protocol (Illumina, San Diego, CA, USA). The analysis was conducted by the Endocrinology Laboratory Service at "Hospital Clínico Universitario de Valencia”. For mapping, we also selected genotypic data of six SSR markers previously evaluated in the same progeny (BPPCT025, BPPCT033, BINEPPCU6377, pchcms5, UCDCH15, and UDP98-024) (Cantín et al. 2010a; Abidi et al. 2012).

Self-pollinated seedlings were identified using homozygous SNP markers with different alleles in both parents. Seedlings with the same genotype as the female parent were excluded from further analysis.

Markers with missing data (in one or both parents), non-polymorphic, redundant, or deviated from the expected segregation proportion were excluded. When markers had the same segregation pattern, only one marker was included to improve computational algorithm efficiency (Van Ooijen 1992).

For the segregation deviation test, a Chi-square test was performed with $p=0.05$ as the threshold (Zeballos et al. 2015). In a second round, the markers were adjusted to a 1:1 segregation ratio with a $p=0.005$ threshold. 


\section{Map construction}

JoinMap®4 software (Van Ooijen 2006) was used to construct the linkage maps as a cross-pollinated population, following the software manual instructions. To use the double pseudo-test cross strategy (Grattapaglia and Sederoff 1994), the option "Create maternal and paternal population nodes" command in JoinMap was used. Two mapping rounds were performed.

A preliminary number of groups and linkage groups (LGs) were established using the recombination fraction criterion (see details in Zeballos et al. 2015). A second mapping round was performed with the selected SNPs by including the SSR markers, the order of markers in each LG was established using the maximum likelihood mapping option, and map distances were calculated using Kosambi's mapping function. Further details regarding genetic map construction can be found in Zeballos (2012).

\section{QTL analysis}

QTL analysis was carried out using R/qtl (v1.22-21) software with the Single-QTLModel (SQM) or Multiple-QTL-Model (MQM) procedures using the R platform (Broman et al. 2003). Single regression (Haley-Knott) was conducted for nonnormalized (non-transformed) traits (pH, TA, RI, Firmness 2007 and Glucose 2009). QTL analyses were performed for each trait separately for each year and with the overall mean (2007-2010). The likelihood of the presence of a QTL was expressed as a $\log$ of odds (LOD) score. LOD significance thresholds were determined with the permutation test procedure; option settings included 1,000 permutations, and significance was set to $p=0.05$. When the LOD score exceeded the significance threshold somewhere along an LG, a segregating QTL was declared. For the confidence interval, we used the "bayesint command" in $\mathrm{R} / \mathrm{qtl}$ with $p=0.90$ and $p=0.95$ for outer and inner interval bounds, respectively (Broman and Saunak 2009). Graphical representation of QTLs on maps was generated with MapChart® v2.2 software (Voorrips 2002).

A multiyear QTL analysis was carried out using QTLNetwork-2.1 software (http://ibi.zju.edu.cn/software/qtlnetwork/) to explore environmental effects and increase accuracy for QTL detection (Yang et al 2008). 


\section{Results}

\section{Phenotyping}

Six out of the 75 initial seedlings of the 'Venus' $\times$ 'Big Top' progeny were identified as self-pollinating. With the SNP markers, a new genotype was identified in addition to the five previously reported as self-pollinated in the same population (Cantín et al. 2010a). Results for the pomological traits evaluated over 4 years (2007-2010) in the remaining seedlings are summarized in Table 1. Wide phenotypic variation was found for most of the traits studied in this progeny (Abidi et al. 2011; Zeballos et al. 2015), which supports the quantitative nature of these traits. Distribution of the traits has been reported as Supplementary Fig. 1. Pearson's correlations between years and traits are summarized in Supplementary Tables 1 and 2. Significant correlations were found in years 2007, 2009 and 2010, high for yield, fruit weight, pH, TA, and RI, and moderate for firmness and SSC. Pearson's coefficients were significant in 2007, 2008 and 2009 for glucose, sorbitol and fructose. The lower correlation values were found for antioxidants in 2007 and sugars (except sorbitol) in 2010, respectively. The evaluated traits showed significant and high correlations for SSC and sugars (total sugars, sucrose, glucose, sorbitol and fructose). Titratable acidity and $\mathrm{pH}$ were highly negatively correlated $(\mathrm{r}=-0.804)$. The higher Pearson's correlations were between total sugars and sucrose $(\mathrm{r}=0.910)$ and total phenolics and flavonoids $(\mathrm{r}=0.828)$.

\section{Marker screening and linkage mapping}

Out of the 8,144 SNPs, 5,323 were non-polymorphic (43 had missing data for either parent and 5,280 were homozygous in both parents), 1,808 showed the same segregation pattern, and 338 presented a distorted segregation. Finally, a total of 675 SNPs were informative, with GenTrain scores that ranged from 0.35 to 0.92 ; of these, 270 SNPs were heterozygous in both parents and therefore discarded from analysis because they were not suitable for this mapping strategy. The final number of selected markers was 405; 223 used for the 'Venus' map and 182 for the 'Big Top' map. Two preliminary dense genetic maps were constructed for 'Venus' and 'Big Top' with 160 and 208 markers, respectively, found on 11 LGs (Zeballos et al. 2015). Final LG assignment was performed after comparison with the peach genome v1.0 physical map 
(GDR, 2015), and markers with identical segregation patterns that were previously excluded were included for the next step (Zeballos 2012). This information was updated with the peach genome v2.0 physical map (Phytozome v11.0, https://phytozome.jgi.doe.gov/pz/portal.html), see Supplementary Table 3). Genetic linkage map of the 'Venus' parent

The second mapping round included 102 SNPs and five SSRs (BPPCT025, BINEPPCU6377, pchcms5, UCDCH15, and UDP98-024). The resulting map grouped 99 SNPs (the remaining three markers were not linked) and five SSRs in nine LGs that spanned $259.9 \mathrm{cM}$ (Fig. 1).The length of the LGs ranged from $1.47 \mathrm{cM}$ to $85.7 \mathrm{cM}$, with an average distance between adjacent markers of $2.49 \mathrm{cM}$. Seven scaffolds were represented in this map (1, 2, 3, 4, 6, 7, and 8). Scaffolds 1 and 2 were split into two LGs, and scaffold 5 was not represented in the female parent map. The marker SNP_IGA_536394 was correctly mapped on LG V6 (Fig. 1) as it was assigned in Peach v2.0 (Pp06, in bold in Supplementary Table 3).

\section{Genetic linkage map of the 'Big Top' parent}

After establishing the most suitable order of markers, the second mapping round placed 122 SNPs and one SSR (BPPCT033) on 10 LGs (Fig. 2). The map spanned $464.3 \mathrm{cM}$, the length of LGs ranged from $1.47 \mathrm{cM}$ to $85.4 \mathrm{cM}$, and the average distance between adjacent markers was $3.8 \mathrm{cM}$. Nine scaffolds were represented in this map $(1,2,3,4,5$, 6, 7, 8, and 13). Scaffolds 1 and 6 were split into two LGs. The marker SNP_IGA_430365 was mapped on LG B7 in contrast with the position assigned on the physical map (scaffold 4 and Pp03, in bold in Supplementary Table 3). The other marker apparently mapped in different scaffold, SNP_IGA_913769 on LG B3 was positioned in chromosome Pp03 in the Peach physical genome v2.0 (in bold in Supplementary Table 3).

\section{QTL analysis}

Using the SQM and MQM methods, at least one QTL was found for 16 out of 17 traits evaluated. No significant QTL was found for vitamin C, although on LG V4, two QTLs that did not overcome the threshold explained more than $10 \%$ of the phenotypic variance (11.5 and 12.8\%, respectively). The list of QTLs with their magnitude of impact across years is presented in Table 2. Analyzing the data by year, 54 QTLs were 
detected and mapped over 12 LGs that represented seven scaffolds (Fig. 3 and Fig. 4). The portion of phenotypic variance explained by each significant QTL ranged between 7.7 and $85.3 \%$ of the total variance (Table 2). When using the multi-year approach QTLs were detected for all traits except for flavonoids (Table 2). For the multi-year analysis, the explained variation was between 0.9 and $71.1 \%$. The fraction of the variation explained for the environmental interaction (VGE) ranged from 0.1 to $12.0 \%$. VGE were below 6\% except for Firmness (12\%) and Anthocyanin content (8\%). In both parental maps, QTLs were found for fruit weight; firmness; SSC; total sugar, sucrose, sorbitol, fructose, total phenolic and flavonoid contents; and RAC (Table 2). Production (yield, $\mathrm{Kg} /$ tree), and glucose content were mapped only onto the 'Venus' map (Table 2 and Fig. 3), whereas QTLs for pH, TA, RI, and anthocyanin content were only mapped onto the 'Big Top' map (Table 2 and Fig. 4). QTLs detected for fruit weight, $\mathrm{pH}, \mathrm{TA}, \mathrm{RI}$, and sorbitol content explained more than $50 \%$ of the variance, and had LOD scores values up to 18.0, 28.0, 27.6, 21.6, and 22.2, respectively (Table 2). The number of QTLs found over each LG in the different years of evaluation varied between one and 20. In the 'Venus' map (Table 2 and Fig. 3), LGs V1_1, V2_1, V3, V7, and V8 had only one QTL, LG V2_2 had four, and LG V4 had 19 QTLs. In the 'Big Top' map (Table 2 and Fig. 4), LGs B1_2 and B4 had only one QTL, LGs B2 and B8 had two, and LG B5 had 20 QTLs that controlled different traits.

With regard to the QTLs identified based on mean value (not shown in Fig. 3 and Fig. 4), most of the traits were consistently significant over time (Table 2, Supplementary Table 4). For example, for fruit weight, QTLs identified on LG V4 in the yearly analysis were in the same region as QTLs detected with the mean or multi-year analysis. Similar situations were observed in QTLs for firmness, SSC, and for sorbitol content, which were mapped in the same position on LG V4 (Table 2, Supplementary Table 4). On LG B5, QTLs for the traits $\mathrm{pH}$; TA; RI; and sucrose, and anthocyanin contents were mapped at the same position as the mean and the multi-year analysis (Table 2). Some QTLs, such as those for glucose and flavonoid contents, did not appear when using mean value, even though they were identified in analysis across multiple years. However, some QTLs were mapped based only on the mean value such as for production, and total phenolic content (qPDR.V-Ch3-Mean and qPHE.V-Ch4-Mean, respectively), or only detected by the multi-year analysis (qPDR.V-Ch1_2- MYear, qPDR.V-Ch4- MYear, qGLU.BT-Ch3-MYear, and qFRU.BT-Ch8- MYear). 
We identified a region on LG V8 with two QTLs that are potentially involved in production; the LOD score, additive effect, and proportion of phenotypic variance explained by qPDR.V-Ch8-2010 and qPDR.V-Ch8-Mean confirm the genetic control of this region on yield. Furthermore, three QTLs for fruit weight on LG V4 (qFW.V-Ch42007, 2009 and 2010) identified across 3 years (Table 2, Fig. 3, and Supplementary Table 4) were found in the same region as the mean, also confirmed with the multiyear analysis, which supports the presence of QTLs influencing fruit weight in both regions (at $46 \mathrm{cM}$ and $60 \mathrm{cM}$ ). In addition, on LG B8, one QTL for fruit weight (qFW.BT-Ch82010) was also identified in 2010, and another QTL was observed using the mean value (qFW.BT-Ch8-Mean), also identified with the multi-year analysis (qFW.BT-Ch8MYear).

For firmness, we identified two QTLs on LG V4 and two other QTLs on LG B5. The first region (qFF.V-Ch4-2007 and 2009) was on LG V4 had QTLs within an 8-cM interval (Table 2). The QTLs mapped on LG B5 (qFF.BT-Ch5-2009 and 2010) were 9 cM apart, but the position was confirmed with the QTLs detected using the mean value (qFF.BT-Ch5-Mean, $12 \mathrm{cM}$ ) and with the multiyear analysis (qFF.BT-Ch5-MYear, $10.9 \mathrm{cM})$. Furthermore, eight QTLs were detected and mapped for SSC across different years; five (qSSC.V-Ch4-2007a, 2007b, 2009a, 2009b, and 2010) were on LG V4, one (qSSC.V-Ch2_2-2009) on LG V2_2, and two (qSSC.BT-Ch5-2009 and 2010) on LG B5 (Table 2 and Fig. 3). On LG V4, two different regions (at 29-32 and 44 cM) were simultaneously repeated in 2007 and 2009, which indicates the presence of two different QTLs. Only the second position was confirmed with the mean value and the multi-year analysis (Table 2). On LG B5, two QTLs (qSSC.BT-Ch5-2009 and 2010) were detected, and the QTL with the mean value (qSSC.BT-Ch5-Mean) and the multi-year analysis (qSSC.BT-Ch5-MYear) were in the middle.

QTLs for pH, TA, and RI (SSC/TA) were exclusively mapped over LG B5 and around the same region. The proportions of phenotypic variances explained by these QTLs varied from 42.4 to $85.3 \%$. QTLs for pH (qpH.BT-Ch5-2007, 2009, 2010) were located at the same genomic region across 3 years, and the same position was detected with the mean pH value (Table 2, Supplementary 4) and the multi-year analysis. TA was mapped on LG B5 at 2-3 cM across 3 years and with the mean (qTA.BT-Ch5-2007, 2009, 2010, and Mean). However, two positions were detected with the multiyear analysis (qTA.BTCh5-MYear-a and $\mathrm{b}$ at 2.9 and $53.7 \mathrm{cM}$ ). RI was not previously mapped on any peach 
map, and because this trait is a function of SSC and TA, it is correlated with both traits. Three QTLs were found on LG B5 during 3 years (2007, 2009, and 2010), and the QTL in 2009 (qTA.BT-Ch5-2009) was repeatedly observed using the mean value (qTA.BTCh5-Mean) and with the multi-year analysis (qTA.BT-Ch5-MYear). QTLs for total sugar, sucrose, glucose, sorbitol, and fructose contents were mainly found in LGs V4 and B5 (Table 2, Fig. 3 and Fig. 4). These QTLs were mapped at short distance intervals for each trait. In addition, some QTLs detected with the mean value were placed at the same or very close positions as other QTLs detected across years and with the multi-year analysis (Table 2). Remarkably, high LOD scores were obtained for qSOR.V-Ch4-2007, and 2009 (12.9 and 18.6, respectively), and the high values of phenotypic variances were explained by the nearest markers (51.2, and 57.7, respectively).

The QTLs identified for phenolic compounds were mainly on LGs B2, V2_2, V4, and B5. QTLs for total phenolic and flavonoid contents were found in both parents and distributed on different LGs, and none of them were repeated over the years studied (Table 2). Alternatively, QTLs for anthocyanin content were identified at the same position on LG B5 for 2 years with the mean value also validated with the multi-year analysis (Table 2 and Fig. 4). The QTLs detected for RAC on LGs V4, were validated with the multi-year analysis.

\section{Discussion}

\section{Genetic maps}

This work presents the first genetic map of the nectarine population 'Venus' $\times$ 'Big Top' with 'IPSC 9K peach SNP array v1'. Two preliminary studies carried out in the same population mapped 17 SSR markers on LG4 (Cantín et al. 2010a) and six on LG6 (Abidi et al. 2012). In the present map, LG4 includes a total of 36 markers, with 26 and 10 markers in the 'Venus' and 'Big Top' maps, respectively. LG6 included a total of 39 markers, with 21 markers in the 'Venus' map and 18 markers distributed in two LGs in the 'Big Top' map. SNPs allow increased saturation and genome coverage and therefore provide higher precision and accuracy for QTL dissection in this population, as was found in other Prunus progenies (Eduardo et al. 2013; Martínez-García et al. 2013b; Da Silva-Linge et al. 2015). 
Both genetic maps had more than eight LGs, which is the expected number of chromosomes in Prunus persica. Scaffolds 1 and 2 in the 'Venus' map and scaffolds 1 and 6 in the 'Big Top' map were split into two LGs. The absence of linkage between markers that belong to the same chromosome is common in genetic mapping (Chaparro et al. 1994; Dirlewanger et al. 1998; Zhebentyayeva et al. 2008; Eduardo et al. 2013). To our knowledge, this is the sixth full map produced with the 'IPSC 9K peach SNP array v1' in peach, although others have been constructed with this array technology in other Prunus-derived progenies (Eduardo et al. 2013; Yang et al. 2013; Martínez-García et al. 2013a; Frett et al. 2014; Pacheco et al. 2014; Romeu et al. 2014; Da Silva-Linge et al. 2015; Nuñez-Lillo et al. 2015). The length of genetic linkage maps mostly based on SNP markers were more saturated compared with the previously published maps, with the exception of the $\mathrm{T} \times \mathrm{E}$ Prunus reference map (Dirlewanger et al. 2006). In our population, 104 SNPs were mapped in 'Venus' and 122 in 'Big Top', which spanned $259 \mathrm{cM}$ in the 'Venus' map and $464 \mathrm{cM}$ in the 'Big Top' map. Other maps have been developed using 'IPSC 9K peach SNP array v1' in different F1 populations. Eduardo et al. (2013) analyzed 'Bolero' $\times$ 'OroA' progeny and obtained two maps with 231 and 87 markers in nine and five LGs, which span 405 and $228.5 \mathrm{cM}$, for the 'Bolero' and 'OroA' maps, respectively. Romeu et al. (2014) found less saturation on 'V6' and 'Granada' maps (178 SNPs and 76 SNPs that span 480 and $276 \mathrm{cM}$, representing 2.94 and $3.87 \mathrm{cM} /$ marker, respectively). Furthermore, two dense maps constructed with other SNP markers in peach- and peach-almond-derived progenies spanned 422 and $369 \mathrm{cM}$, respectively (Martínez-García et al. 2013b). The average marker density in the previously mentioned maps was similar and comparable to our results, although in some cases the genome was not entirely covered (Romeu et al. 2014; Sánchez et al. 2014). Scaffolds 1, 2, and 6 with unsaturated regions explain the absence of linkage (Fig, 1) and why two LGs were found on one chromosome. Scaffold 1 split into two LGs in both parents, scaffold 2 was in the 'Venus' map, and scaffold 6 was in the 'Big Top' map. Different authors revealed unsaturated regions in scaffolds 1, 2, 4, and 5 (Frett et al. 2014), and 4, 5, 7, and 8 (Sánchez et al. 2015). Moreover, Sánchez et al. (2014) found that chromosomes 2,1 , and 3 were missing in a pseudo-test cross population between the cultivars 'MxR_01' and 'Granada'. The lack of polymorphic SNPs in certain chromosomes is caused by homozygosis in the peach genome and is probably due to germplasm background (Romeu et al. 2014; Sánchez et al. 2014; Nuñez-Lillo et 
al. 2015). Verde et al. (2012) evaluated and validated the SNP array and reported common gaps in chromosomes 1,2, and 5. These unsaturated sections may represent putative centromeric regions that would explain these events. Anchoring to the reference genome sequence (Verde et al. 2013), the putative order of the SNPs in our map was initially established in Mbp by comparison with the physical map v1.0. Although assembly and orientation mistakes have been somehow accumulated in the sequence genome, in general marker order in our maps was in agreement with peach genome sequence v1.0 (Supplementary Table 3). In this work, three markers unexpectedly occurred on different LGs compared with the putative order established in the array: SNP_IGA_536394 on LG V6, SNP_IGA_430365 on LG B7, and SNP_IGA_913769 on LG B3. Nevertheless by comparison with the physical map v2.0, all markers were reassigned to their correct chromosome except SNP_IGA_430365 that was positioned on chromosome Pp03 (Supplementary Table 3). The new position on LG B3 for SNP_IGA_913769, which was physically located in scaffold 13 on peach genome v1.0, was confirmed with genome assembly v2.0. As a conclusion, the refinements included in the updated peach genome version v2.0 have confirmed chromosome positions determined in our genetic maps.

Other changes related to the putative order of the SNPs were corrected by comparison with the peach physical map v2.0 (one inversion on LG B1_1 and order for B7 and B8) (see Supplementary Table 3). Moreover, we confirmed a new orientation for chromosomes 2 and 7 by comparing mapped markers on B2 and B7 chromosomes with their positions in the peach physical map v2.0. It is expected to correct the changes described in peach populations mapped with the same SNP array and methodology (Eduardo et al. 2013; Romeu et al. 2014; Sánchez et al. 2014; Da Silva-Linge et al. 2015). As it was previously mentioned pseudomolecule 2 was wrongly mapped in $\mathrm{T} \times \mathrm{E}$ (Verde et al. 2013), and inversions and translocations have been commonly described on chromosomes, LG1, LG2, LG4, LG7, and LG8 (Eduardo et a. 2013; Martínez-García et al. 2013b; Da Silva-Linge et al. 2015). Finally, lack of markers on V5 may be due to identity by descent or ascertainment biases in the SNP markers represented in the array (Nielsen et al. 2004; Albrechtsen et al. 2010), as discussed by Eduardo et al. (2013). However, other specific characteristic of the population, such as size, genetic background, or any other unknown particularity may be affected. 


\section{QTL analysis}

Based on the results in our population, even though the progeny size is limited, we identified important regions in the peach genome that control fruit quality traits. Many of the QTLs detected in our progeny were previously found in other peach mapping populations. However, we described 16 QTLs that control peach fruit quality traits for the first time (one for production, fruit weight, firmness and total sugar and sucrose contents; two for total phenolic anthocyanin contents, and RAC; and five for flavonoid content). Five of them were validated with the multi-year approach.

The precision of phenotypic evaluation is very important for accurate QTL mapping. A reliable QTL map can only be produced from reliable phenotypic data. Replicated phenotypic evaluations during different years improve the accuracy of QTL mapping by reducing experimental error and background noise (Salazar et al. 2013). Most of the QTLs found in our study were consistent for at least 2 years and were detected also with the multi-year analysis, although others were not repeated across all 4 years of study. The multi-year approach allowed the detection of QTLs that were not considered significant by doing single-year analysis (Dirlewanger et al. 2012). The characteristics of these QTLs are included in Table 2 and Supplementary Table 4. Variation in QTL position over time is commonly found in QTL analysis, and similar performance, including non-repetitiveness of QTLs across different years, different locations found in yearly analyses, and detection with the mean value, as reported by other authors for peach and other Prunus species (Dirlewanger et al. 1999; Etienne et al. 2002; Verde et al. 2002; Quilot et al. 2004; Eduardo et al. 2011; Dirlewanger et al. 2012; Salazar et al. 2013).

The QTL that controls peach production found on LG V8 is reported for the first time. No other authors have evaluated this trait as yield in terms of $\mathrm{Kg} /$ tree, although Dirlewanger et al. (1999) reported a QTL on LG6 for productivity (number of fruits per tree), which is a somewhat related trait in terms of overall productivity. However, from an agronomical point of view, these are separate traits. A remote possibility exists that these QTLs could be related to a translocation between LG6 and LG8, as was reported in the $F_{2}$ 'Garfi' × 'Nemared' population (Jáuregui et al. 2001). For fruit weight, as we found in the 'Venus' $\times$ 'Big Top' population, some authors have identified QTLs on LG1, LG2, LG4, and LG6 in other mapping populations in peach (Quilot et al. 2004; 
Eduardo et al. 2011; Fresnedo-Ramírez et al. 2015). However, newly discovered QTLs that control peach fruit weight were reported for the first time on LG7 (Da Silva-Linge et al. 2015), LG5 (Fresnedo-Ramírez et al. 2015) and LG8 (qFW.BT-Ch8-2010). The QTLs qFW.V-Ch4-2009 and 2010 for fruit weight found on LG V4 were located on the same genomic region across multiple years, with the nearest marker at $45 \mathrm{cM}$. This indicates the presence of a single QTL on LG V4 for this trait also confirmed with the mean and the multi-year analysis. The QTL qFW.V-Ch4-2007 (60 cM) was also confirmed with the multi-year analysis $(62.1 \mathrm{cM})$. The other QTL, located on B8, had a high LOD score and explained an important part of the variation, which was only detected in $2010(25 \mathrm{cM})$ but partially confirmed with the mean $(9 \mathrm{cM})$ and the multiyear analysis $(16 \mathrm{cM})$. The low saturation in this region of the chromosome is one possible explanation for these results.

The QTLs for firmness on LG V4 (qFF.V-Ch4-2007 and 2009) and LG B5 (qFF.BTCh5-2009 and 2010) potentially represent two single QTLs that were validated with the mean (qFF.V-Ch4-Mean) and multi-year analysis (qFF.V-Ch4-MYear; qFF.BT-Ch5MYear). The QTLs found for firmness on LG V4 (qFF.V-Ch4-2009 and mean) were previously reported by Cantín et al. (2010a) in the same population. Furthermore, for SSC, we found different genomic regions on LG4, as other authors have previously identified in peach (Abbott et al. 1998; Dirlewanger et al. 1999; Quarta et al. 2000; Etienne et al. 2002; Quilot et al. 2004; Cantín et al. 2010a; Eduardo et al. 2011; Sánchez et al. 2014). Cantín et al. (2010a) found a QTL for SSC on LG4 that explained more than $80 \%$ of the total variation using SSR markers and composite interval mapping for QTL mapping in this population. Two QTLs on LG4 could explain the variation in total SSC. The first region (qSSC.V-Ch4-2007a, 2009a) explained less than 19\% of phenotypic variance, and the second (qSSC.V-Ch4-2007b, 2009b, and 2010) explained 28.0, 27.6, and $21.4 \%$ of the total variance, respectively. The second region was confirmed with the mean value at $44 \mathrm{cM}$ and validated at the same position with the multi-year analysis. Other genomic regions that control SSC on LG V2_2 (qSSC.VCh2_2-2009) and LG B5 (qSSC.BT-Ch5-2009 and 2010) were also reported in other populations and were found on LG2 in peach (Verde et al. 2002; Quilot et al. 2004; Eduardo et al. 2011) and LG5 in peach (Quilot et al. 2004) and apricot (Salazar et al. 2013) and both LGs in peach and Prunus related progenies (Fresnedo-Ramírez et al. 2015). Many QTLs have been previously described for SSC because it is one of the 
most widely studied traits; SSC is used as a standard universal method to define quality in fruits and it is a quick and simple evaluation method.

Other major QTLs that control pH and TA were found only on in the 'Big Top' map on LG5. The additive effect and proportion of total variance explained by these QTLs (up to $85 \%$ ) revealed which regions control these traits. Moreover, these QTLs had a consistent position relative to the $D$ gene, which controls lack of acidity in fruit (Abbott et al. 1998; Dirlewanger et al. 1998; 2004). For TA, other authors mapped QTLs in the proximal part of LG5 (Dirlewanger et al. 1999; Etienne et al. 2002), as was found on the 'Big Top' map (qTA.BT-Ch5-2007, 2009 and 2010). Another position at $53.7 \mathrm{cM}$ was also detected in our population with the multi-year analysis (qTA.BT-Ch5-MYear). Quilot et al. (2004) identified a QTL associated with TA at 52 cM on LG5 when mapping two interspecific populations. These positions are also consistent with markers developed for sub-acidic traits in peach (Eduardo et al. 2014) and with the colocalization of QTLs for TA and pH on LG5 (Fresnedo-Ramírez et al. 2015). On the contrary, any equivalent QTL on LG5 was found in apricot for malic acid (which is synonymous with TA) and pH (Salazar et al. 2013), even in peach (Eduardo et al. 2011). The position of the QTLs found for RI (SSC/TA) indicates that TA has more influence than SSC in the genetic control of this trait, because the QTLs were in the same position as acidity (TA) (Table 2). This fact was also confirmed with the significant correlations found between these traits (Supplementary Table 2). Some of the QTLs that control total sugar content, which explain more than $15 \%$ of phenotypic variance, were detected across 2009 and 2010 and were mapped on LG2, LG4 and LG5. QTLs for this trait were previously described on LG2 (Quarta et al. 2000; Quilot et al. 2004) and LG5 (Quilot et al 2004) but never on LG4. However, in this study only the region that controls total sugar content on LG5 was repeated with the mean and validated with the multi-year approach.

For sucrose content, the QTL detected on LG B5 (qSUC.BT-Ch5-2007) was consistent with the QTLs found with the mean and the multi-year analysis (Table 2, Supplementary Table 4, and Fig. 4), which indicates the presence of a major QTL that controls this trait. QTLs for sucrose were previously described on LG3, LG5, LG6, and LG7 (Dirlewanger et al. 1999; Etienne et al. 2002; Quilot et al. 2004). LG4 was not previously reported to control sucrose content in peach. In addition, the QTLs that control glucose and fructose contents found on LG V4 at $48 \mathrm{cM}$ were consistent with 
the QTLs found at the same position with the multi-year analysis. The LOD scores and percent of total variance found also indicate the existence of a major QTL that controls glucose and fructose contents on LG4 as previously detected in other peach mapping populations (Abbott et al. 1998; Dirlewanger et al. 1999; Etienne et al. 2002; Quilot et al. 2004). The QTLs found for fructose content were also previously reported by various authors on LG5 (Abbott et al. 1998; Dirlewanger et al. 1999), and on LG1 and LG2 (Quilot et al. 2004).

The four QTLs that control sorbitol content were in a cluster located on LG 4 between 45 and $54 \mathrm{cM}$ in the map. The high LOD scores and total phenotypic variance explained by these QTLs across the 4 years indicates the presence of a major QTL on LG4 that controls sorbitol content also consistent with the mean and the multi-year approach. QTLs for sorbitol were previously described on LG2, LG4, and LG5 (Dirlewanger et al. 1999; Quilot et al. 2004), however, any QTL on LG2 was found in this study. Finally, QTLs for total phenolic and flavonoid contents were mapped on LG2 in both parental maps. The proximity of the nearest assigned markers indicates that a single QTL on LG2 controls phenolic content. It is very well known that flavonoids are highly correlated with phenolic content ( $\mathrm{r}=0.828$; Supplementary Table 2) because flavonoids belong to this family (Cantín et al. 2009b; Abidi et al. 2011; Font i Forcada et al. 2013). The observation that QTLs of RAC, total phenolics, and flavonoid contents reside at the same position on LG4 indicates that most RAC activity is related to flavonoid content ( $\mathrm{r}=0.761$; Supplementary Table 2), as was previously reported (Cantín et al. 2009b; Abidi et al. 2011; Font i Forcada et al. 2013). Other QTLs for antioxidant compounds were found on other LGs (V3, V7, B5 and B8). Only QTLs that control anthocyanin content were consistent over 2 years on LG B5, and confirmed with the mean and validated with the multi-year approach.

Considering the synteny between Prunus and Malus (Dirlewanger et al. 2004; Arús et al. 2012), in our progeny, the QTLs detected that control phenolic content were not located in the same genomic regions as in apple (Chagné et al. 2012, Verdu et al. 2014). Chagné et al. (2012) found QTLs for flavonoid and anthocyanin contents on LG16 (syntenic with LG6 and part of LG1 in Prunus), anthocyanin content on LG9, and phenolic content on LG17 (both syntenic with LG3) and LG15 (syntenic with part of LG1). Other positions have been found in cider apples for anthocyanin content on LG5 (syntenic with LG4) and flavonoid content on LG15 and LG17 (part of LG1 and LG3 in 
Prunus, respectively). All of these data indicate that the genomic regions that control polyphenols in the Rosaceae family are not entirely conserved.

Our results provide the first insights into the genetic control of total phenolic content in peach. Mapping of QTLs for polyphenolic content provides important knowledge for future studies to develop new cultivars with increased antioxidant properties.

\section{Conclusions}

We report, for the first time, the identification of QTLs for fruit quality traits in 'Venus' × 'Big Top' progeny using 'IPSC 9K peach SNP array v1', which was developed by Illumina. We detected 54 QTLs that represent 34 genomic regions across 4 years of evaluation using the SQM and MQM mapping strategies. We found new and stable QTLs for fruit weight, firmness, total phenolic and anthocyanin contents, and relative antioxidant capacity in peach. LGs V4 in 'Venus' and B5 in 'Big Top' contained the most important genomic regions that control fruit quality traits in peach. The colocalization and clustering of the majority of the detected QTLs might indicate that these genes are tightly linked. In some cases, pleiotropic effects may occur. Furthermore, the multi-year approach helped to confirm and detect minor QTLs or QTLs from traits potentially affected by climatic conditions.

The results presented in this work enhance the existing maps developed with the same SNP array and open the possibility of using marker-assisted selection to improve fruit quality in peach. Further studies must be carried out to validate the QTLs revealed here to identify new candidate genes in peach. Moreover, these data will facilitate the development of new peach cultivars that bear fruit with increased concentrations of polyphenolic compounds that benefit human health.

\section{Acknowledgments}

We are grateful to C.H. Crisosto (University of California, Davis) for providing SSR markers (UCDCH15 and BINEPPCU6377). We thank E. Sierra and S. Segura for technical assistance and plant management in the field and N. Ksouri for bioinformatic assistance. We are grateful to A. Casas and E. Igartua for assistance and support with the statistical analysis using JoinMap®4 software. This study was funded by the Spanish Ministry of Economy and Competitiveness (MINECO) grants AGL-2008-00283, AGL201124576, and AGL2014-52063-R and co-funded by FEDER and the Regional Government of Aragón (A44) with European Social Fund. W. Abidi was supported by a JAE-Pre fellowship from Consejo Superior de 
Investigaciones Científicas (CSIC), which enabled him to visit the University of California, Davis, and IBMCP-Valencia Spain. J.L. Zeballos received a Master fellow funded by the Spanish Agency for International Cooperation and Development (AECID).

\section{Data archiving statement}

$\mathrm{V} \times \mathrm{BT}$ linkage maps and QTL positions are available on Genome Database for Rosaceae at tfGDR1025 accession number.

\section{References}

Abbott AG, Rajapakse S, Sosinski B, Lu ZX, Sossey-Alaoui K, Gannavarapu M, Reighard G, Ballard RE, Baird WV, Scorza R, Callahan A (1998) Construction of saturated linkage maps of peach crosses segregating for characters controling fruit qualtiy, tree architecture and pest resistance. Acta Hortic 465:41-50

Abidi W, Jiménez S, Moreno MÁ, Gogorcena Y (2011) Evaluation of antioxidant compounds and total sugar content in a nectarine [Prunus persica (L.) Batsch] progeny. Int J Mol Sci 12:6919-6935

Abidi W, Cantín C, Gonzalo MJ, Moreno MA, Gogorcena Y (2012) Genetic control and loction of QTLs involved in antioxidant capacity and fruit quality traits in peach [Prunus persica (L.) Batch]. Acta Hortic 962:129-134

Abidi W, Cantín CM, Jiménez S, Giménez R, Moreno MA, Gogorcena Y (2015) Effect of antioxidant compounds and total sugars and genetic background on the chilling injury susceptibility of a non-melting peach [Prunus persica (L.) Batsch] progeny. J Sci Food Agric 95:351-358

Albrechtsen A, Nielsen FC, Nielsen R (2010) Ascertainment biases in SNP chips affect measures of population divergence. Mol Biol Evol 11:2534-2547

Arús P, Verde I, Sosinski B, Zhebentyayeva T, Abbott AG (2012) The peach genome. Tree Genet Genomes 8:531-547

Boeing H, Bechthold A, Bub A, Ellinger S, Haller D, Kroke A, Leschik-Bonnet E, Müller M J, et al. (2012) Critical review: vegetables and fruit in the prevention of chronic diseases. Eur J Nutr 51:637-663

Brem RB, Kruglyak L (2005) The landscape of genetic complexity across 5,700 gene expression traits in yeast. Proc Natl Acad Sci USA 102:1572-1577

Broman KW, Saunak S (2009) A Guide to QTL Mapping with R/qtl. Statistic for Biology and Helth. Springer, New York. doi:10.1007/978-0-387-92125-9

Broman KW, Wu H, Sen Ś, Churchill GA (2003) R/qt1: QTL mapping in experimental crosses. Bioinformatics 19:889-890

Byrne DH, Raseira MB, Bassi D, Piagnani MC, Gasic K, Moreno MA, Pérez S (2012) Peach. In: Badenes ML, Byrne DH (eds) Fruit breeding, vol 8. Handbook of plant breeding. Springer, New York, pp 505-569

Cantín CM, Gogorcena Y, Moreno MA (2009a) Analysis of phenotypic variation of sugar profile in different peach and nectarine [Prunus persica (L.) Batsch] breeding progenies. J Sci Food Agric 89:1909-1917. 
Cantín CM, Moreno MA, Gogorcena Y (2009b) Evaluation of the antioxidant capacity, phenolic compounds, and vitamin $\mathrm{C}$ content of different peach and nectarine [Prunus persica (L.) batsch] breeding progenies. J Agric Food Chem 57:45864592

Cantín CM, Crisosto CH, Ogundiwin EA, Gradziel T, Torrents J, Moreno MA, Gogorcena Y (2010a) Chilling injury susceptibility in an intra-specific peach [Prunus persica (L.) Batsch] progeny. Postharvest Biol Technol 58:79-87

Cantín CM, Gogorcena Y, Moreno MA (2010b) Phenotypic diversity and relationships of fruit quality traits in peach and nectarine [Prunus persica (L.) Batsch] breeding progenies. Euphytica 171:211-226

Crisosto CH (2002) How do we increase peach consumption? Acta Hortic 592:601-605

Chagné D, Krieger C, Rassam M, Sullivan M, Fraser J, André C, Pindo M, Troggio M, Gardiner SE, Henry RA, Allan AC, McGhie TK, Laing WA (2012) QTL and candidate gene mapping for polyphenolic composition in apple fruit. BMC Plant Biol 12:1-16

Chaparro JX, Werner DJ, O'Malley D, Sederoff RR (1994) Targeted mapping and linkage analysis of morphological isozyme, and RAPD markers in peach. Theor Appl Genet 87:805-815

Da Silva-Linge C, Bassi D, Bianco L, Pacheco I, Pirona R, Rossini L (2015) Genetic dissection of fruit weight and size in an F2 peach (Prunus persica (L.) Batsch) progeny. Mol Breed 35:71

Davey MW, Kenis K, Keulemans J (2006) Genetic control of fruit vitamin C contents. Plant Physiol 142:343-351

Dirlewanger E, Pronier V, Parvery C, Rothan C, Guye A, Monet R (1998) Genetic linkage map of peach [Prunus persica (L.) Batsch] using morphological and molecular markers. Theor Appl Genet 97:888-895

Dirlewanger E, Moing A, Rothan C, Svanella L, Pronier V, Guye A, Plomion C, Monet $\mathrm{R}$ (1999) Mapping QTLs controlling fruit quality in peach (Prunus persica (L.) Batsch). Theor Appl Genet 98 (1):18-31

Dirlewanger E, Graziano E, Joobeur T, Garriga-Calderé F, Cosson P, Howad W, Arús P (2004) Comparative mapping and marker-assisted selection in Rosaceae fruit crops. Proc Natl Acad Sci USA 101:9891-9896

Dirlewanger E, Cosson P, Renaud C, Monet R, Poëssel JL, Moing A (2006) New detection of QTLs controlling major fruit quality components in peach. Acta Hortic 713:65-72

Dirlewanger E, Quero-García J, Le Dantec L, Lambert P, Ruiz D, Dondini L, Illa E, Quilot-Turion B, Audergon JM, Tartarini S, Letourmy P, Arús P (2012) Comparison of the genetic determinism of two key phenological traits, flowering and maturity dates, in three Prunus species: Peach, apricot and sweet cherry. Heredity 109:280-292

Eduardo I, Pacheco I, Chietera G, Bassi D, Pozzi C, Vecchietti A, Rossini L (2011) QTL analysis of fruit quality traits in two peach intraspecific populations and importance of maturity date pleiotropic effect. Tree Genet Genomes 7:323-335

Eduardo I, Chietera G, Pirona R, Pacheco I, Troggio M, Banchi E, Bassi D, Rossini L, Vecchietti A, Pozzi C (2013) Genetic dissection of aroma volatile compounds from the essential oil of peach fruit: QTL analysis and identification of candidate genes using dense SNP maps. Tree Genet Genomes 9:189-204 
Eduardo I, López-Girona E, BatlIe I, Reig G, Iglesias I, Howad W, Arús P, Aranzana MJ (2014) Development of diagnostic markers for selection of the subacid trait in peach. Tree Genet Genomes 10:1695-1709

Eduardo I, Picañol R, Rojas E, BatlIe I, Howad W, Aranzana MJ, Arús P (2015) Mapping of a major gene for the slow ripening character in peach: co-location with the maturity date gene and development of a candidate gene-based diagnostic marker for its selection. Euphytica 205:627-636

Etienne C, Rothan C, Moing A, Plomion C, Bodénès C, Svanella-Dumas L, Cosson P, Pronier V, Monet R, Dirlewanger E (2002) Candidate genes and QTLs for sugar and organic acid content in peach [Prunus persica (L.) Batsch]. Theor Appl Genet 105:145-159

FAOSTAT (2015). Food and Agriculture Organization of the United Nations. http://faostat.fao.org/site/291/default.aspx. Accessed August 12015

Font i Forcada C, Oraguzie N, Igartua E, Moreno MA, Gogorcena Y (2013) Population structure and marker-trait associations for pomological traits in peach and nectarine cultivars. Tree Genet Genomes 9:331-349

Fresnedo-Ramírez J, Bink MCAM, van der Weg E, Famula TR, Crisosto CH, Frett TJ, Gasic K, Peace CP, Gradziel TM (2015) QTL mapping of pomological traits in peach and related species breeding germplasm. Mol Breed 35:166

Frett T, Reighard G, Okie W, Gasic K (2014) Mapping quantitative trait loci associated with blush in peach [Prunus persica (L.) Batsch]. Tree Genet Genomes 10:367381

GDR (2015) Genome database for Rosaceae http://www.rosaceae.org/species/prunus_persica/genome_v1.0. Accessed 13, November 2015

Grattapaglia D, Sederoff R (1994) Genetic linkage maps of Eucalyptus grandis and Eucalyptus urophylla using a pseudo-testcross: Mapping strategy and RAPD markers. Genetics 137:1121-1137

Illa E, Eduardo I, Audergon JM, Barale F, Dirlewanger E, Li X, Moing A, Lambert P, Le Dantec L, Gao Z, Poëssel JL, Pozzi C, Rossini L, Vecchietti A, Arús P, Howad W (2011) Saturating the Prunus (stone fruits) genome with candidate genes for fruit quality. Mol Breed 28 (4):667-682

Infante R, Farcuh M, Meneses C (2008) Monitoring the sensorial quality and aroma through an electronic nose in peaches during cold storage. J Sci Food Agric 88:2073-2078

Jáuregui B, De Vicente MC, Messeguer R, Felipe A, Bonnet A, Salesses G, Arús P (2001) A reciprocal translocation between 'Garfi' almond and 'Nemared' peach. Theor Appl Genet 102:1169-1176

Martin C, Zhang Y, Tonelli Ch, Petroni K (2013) Plants, diet, and health. Annu Rev Plant Biol 64:19-46

Martínez-García PJ, Fresnedo-Ramírez J, Parfitt DE, Gradziel TM, and Crisosto CH (2013a) Effect prediction of identified SNPs linked to fruit quality and chilling injury in peach [Prunus persica (L.) Batsch]. Plant Mol Biol 81:161-174

Martínez-García PJ, Parfitt DE, Ogundiwin EA, Fass J, Chan HM, Ahmad R, Lurie S, Dandekar A, Gradziel TM, Crisosto CH (2013b) High density SNP mapping and QTL analysis for fruit quality characteristics in peach (Prunus persica L.). Tree Genet Genomes 9:19-36.

Nielsen R, Hubisz MJ, Clark AG (2004) Reconstituting the frequency spectrum of ascertained single-nucleotide polymorphism data. Genetics 168:2373-2382 
Nuñez-Lillo G, Cifuentes-Esquivel A, Troggio M, Micheletti D, Rodrigo Infante R, Campos-Vargas R, Orellana A, Blanco-Herrera F, Meneses C (2015)

Identification of candidate genes associated with mealiness and maturity date in peach [Prunus persica (L.) Batsch] using QTL analysis and deep sequencing. Tree Genet Genomes 1:86

Ogundiwin EA, Peace CP, Gradziel TM, Parfitt DE, Bliss FA, Crisosto CH (2009) A fruit quality gene map of Prunus. BMC Genomics 10:587

Orazem P, Stampar F, Hudina M (2011) Quality analysis of 'Redhaven' peach fruit grafted on 11 rootstocks of different genetic origin in a replant soil. Food Chem 124 (4):1691-1698

Pacheco I, Bassi D, Eduardo I, Ciacciulli A, Pirona R, Rossini L, Vecchietti A (2014) QTL mapping for brown rot (Monilinia fructigena) resistance in an intraspecific peach (Prunus persica L. Batsch) F1 progeny. Tree Genet Genomes 10: DOI 10.1007/s11295-014-0756-7

Peace C, Norelli J (2009) Genomics approaches to crop improvement in the Rosaceae. In: Folta KM, Gardiner SE (eds) Genetics and genomics of Rosaceae, vol 6. Plant genetics and genomics: Crops and models. Springer New York, pp 19-53

Pirona R, Eduardo I, Pacheco I, Da Silva-Linge C, Miculan M, Verde I, Tartarini S, Dondini L, Giorgio Pea G, Daniele Bassi D, Rossini L (2013) Fine mapping and identification of a candidate gene for a major locus controlling maturity date in peach. BMC Plant Biol 3:166

Quarta R, Dettori MT, Sartori A, Verde I (2000) Genetic linkage map and QTL analysis in peach. Acta Hortic 521:233-242

Quilot B, Wu BH, Kervella J, Génard M, Foulongne M, Moreau K (2004) QTL analysis of quality traits in an advanced backcross between Prunus persica cultivars and the wild relative species P. davidiana. Theor Appl Genet 109:884-897

Romeu J, Monforte AJ, Sánchez G, Granell A, García-Brunton J, Badenes M, Ríos G (2014) Quantitative trait loci affecting reproductive phenology in peach. BMC Plant Biol 14:52

Ru S, Main D, Evans K, Peace C (2015) Current applications, challenges, and perspectives of marker-assisted seedling selection in Rosaceae tree fruit breeding. Tree Genet Genomes 11:8

Salazar JA, Ruiz D, Egea J, Martínez-Gómez P (2013) Transmission of fruit quality traits in apricot (Prunus armeniaca L.) and analysis of linked quantitative trait loci (QTLs) using simple sequence repeat (SSR) markers. Plant Mol Biol Rep DOI 10.1007/s11105-013-0625-9

Sánchez G, Besada C, Badenes ML, Monforte AJ, Granell A (2012) A non-targeted approach unravels the volatile network in peach fruit. PLoS ONE 7(6):e38992

Sánchez G, Romeu J, García J, Monforte AJ, Badenes M, Granell A (2014) The peach volatilome modularity is reflected at the genetic and environmental response levels in a QTL mapping population. BMC Plant Biology 14:137

Steemers FJ, Chang W, Lee G, Barker DL, Shen R, Gunderson KL (2006) Wholegenome genotyping with the single-base extension assay. Nature Methods 3 (1):31-33. doi:10.1038/nmeth842

Van Ooijen JW (1992) Accuracy of mapping quantitative trait loci in autogamous species. Theor Appl Genet 84:803-811

Van Ooijen JW (2006) JoinMap 4, Software for the calculation of genetic linkage maps in experimental populations. Kyazma B.V., Wageningen, Netherlands 
Verde I, Quarta R, Cedrola C, Dettori MT (2002) QTL analysis of agronomic traits in a BC1 peach population. Acta Hortic 592:291-297

Verde I, Bassil N, Scalabrin S, Gilmore B, Lawley CT, Gasic K, Micheletti D, Rosyara UR, Cattonaro F, Vendramin E, Main D, Aramini V, Blas AL, Mockler TC, Bryant DW, Wilhelm L, Troggio M, Sosinski B, Aranzana MJ, Arús P, Iezzoni A, Morgante M, Peace C (2012) Development and evaluation of a 9k SNP array for peach by internationally coordinated SNP detection and validation in breeding germplasm. PloS one 7 (4):e35668

Verde I, Abbott AG, Scalabrin S, Jung S, Shu SQ, Marroni F, Zhebentyayeva T, et al. (Int Peach Genome I) (2013) The high-quality draft genome of peach (Prunus persica) identifies unique patterns of genetic diversity, domestication and genome evolution. Nat Genet 45:487-U447

Verdu CF, Guyot S, Childebrand N Bahut M, Celton JM, Gaillard S, Lasserre-Zuber P, Troggio M, Guilet D, Laurens F (2014) QTL analysis and candidate gene mapping for the polyphenol content in cider apple. PlosOne 9(10):e107103

Vizzotto M, Porter W, Byrne D, Luis Cisneros-Zevallos L (2014) Polyphenols of selected peach and plum genotypes reduce cell viability and inhibit proliferation of breast cancer cells while not affecting normal cells. Food Chem 164:363-370

Voorrips RE (2002) MapChart: software for the graphical presentation of linkage maps and QTLs. J Hered 93:77-78

Wargovich MJ, Morris J, Moseley V, Weber R, Byrne DH (2012) Developing fruit cultivars with enhanced health properties, in fruit breeding. In: Badenes ML, Byrne DH (eds) Fruit breeding, vol 8. Handbook of plant breeding. Springer, New York, pp 37-68

Yang J, Hu Ch, Hu H, Yu R, Xia Z, Ye X, Zhu J (2008) QTLNetwork: mapping and visualizing genetic architecture of complex traits in experimental populations. Bioinformatics 24(5):721-723

Yang N, Reighard G, Ritchie D, Okie W, Gasic K (2013) Mapping quantitative trait loci associated with resistance to bacterial spot (Xanthomonas arboricola pv. pruni) in peach. Tree Genet Genomes 9:573-586

Zeballos J (2012) Identification of genomic region related to fruit quality traits in peach. Universidad de Lleida, Zaragoza, Spain

Zeballos J, Abidi W, Giménez R, Monforte AJ, Moreno MA, Gogorcena Y (2015) QTL analysis of fruit quality traits in peach [Prunus persica (L.) Batsch] using dense SNP maps. Acta Hortic 1084:703-710

Zhebentyayeva TN, Swire-Clark G, Georgi LL, Garay L, Jung S, Forrest S, Blenda AV, Blackmon B, Mook J, Horn R, Howad W, Arús P, Main D, Tomkins JP, Sosinski B, Baird WV, Reighard GL, Abbott AG (2008) A framework physical map for peach, a model Rosaceae species. Tree Genet Genomes 4:745-756

Zhebentyayeva TN, Fan S, Chandra A, Bielenberg DG, Reighard GL, Okie WR, Abbott AG (2014) Dissection of chilling requirement and bloom date QTLs in peach using a whole genome sequencing of sibling trees from an F2 mapping population. Tree Genet Genomes 10:35-51 


\section{Tables and figures}

Table 1 Units, minimum, maximum and mean values for the pomological traits evaluated in the 'Venus' × 'Big Top' progeny during four years (2007-2010) (partially presented in Zeballos et al. 2015). Data are mean \pm SE $(n=198-257)$

\begin{tabular}{|l|l|r|r|r|r|}
\hline Trait & Units & \multicolumn{1}{|c|}{ Min } & \multicolumn{1}{|c|}{ Max } & \multicolumn{1}{c|}{ Mean } & S.E. \\
\hline Production/yield & $\mathrm{kg} /$ tree & 0.83 & 19.70 & 7.09 & \pm 0.29 \\
Fruit weight (FW) & $\mathrm{g}$ & 69.44 & 375.87 & 185.22 & \pm 3.30 \\
Firmness & Newton & 6.23 & 60.76 & 40.78 & \pm 0.68 \\
Soluble Solids Concentration (SSC) & oBrix (g SS/100 g FW) & 9.20 & 20.20 & 13.36 & \pm 0.13 \\
$\mathrm{pH}$ & $\mathrm{pH}$ units & 3.00 & 4.40 & 3.68 & \pm 0.02 \\
Titratable Acidity (TA) & g malic acid /100 g FW & 0.24 & 1.52 & 0.64 & \pm 0.02 \\
Ripening Index (RI: SSC/TA) & g SS/g malic acid & 7.55 & 66.98 & 25.60 & \pm 0.84 \\
Total sugars & $\mathrm{g} / \mathrm{kg} \mathrm{FW}$ & 45.35 & 160.34 & 86.85 & \pm 1.14 \\
Sucrose & $\mathrm{g} / \mathrm{kg} \mathrm{FW}$ & 23.16 & 109.79 & 57.18 & \pm 0.90 \\
Glucose & $\mathrm{g} / \mathrm{kg} \mathrm{FW}$ & 6.58 & 24.00 & 11.58 & \pm 0.20 \\
Sorbitol & $\mathrm{g} / \mathrm{kg} \mathrm{FW}$ & 1.00 & 18.79 & 5.83 & \pm 0.25 \\
Fructose & $\mathrm{g} / \mathrm{kg} \mathrm{FW}$ & 7.43 & 21.53 & 12.07 & \pm 0.17 \\
Vitamin C & $\mathrm{mg} \mathrm{AsA} / 100 \mathrm{~g} \mathrm{FW}$ & 1.17 & 12.11 & 4.10 & \pm 0.13 \\
Total phenolics & 12.10 & 58.85 & 32.32 & \pm 0.87 \\
Flavonoids & $\mathrm{mg} \mathrm{GAE} / 100 \mathrm{~g} \mathrm{FW}$ & 1.58 & 60.13 & 12.69 & \pm 0.61 \\
Anthocyanins & $\mathrm{mg} \mathrm{CE} / 100 \mathrm{~g} \mathrm{FW}$ & 0.32 & 25.72 & 3.14 & \pm 0.21 \\
Relative Antioxidant Capacity (RAC) & $\mathrm{mg} \mathrm{TE} / \mathrm{kg} \mathrm{FW}$ & 125.31 & 1099.59 & 447.87 & \pm 11.26 \\
\hline
\end{tabular}

Abbreviations: AsA ascorbic acid, GAE gallic acid equivalents, $C E$ catechin equivalents, $C 3 G E$ cyanidin3-glucoside equivalents, $T E$ trolox equivalents, Min minimum value, Max maximum value, S.E. standard error. 
Table 2 QTLs found for agronomic and fruit quality traits detected in the 'Venus' $x$ 'Big Top' progeny.

Trait, QTL name and QTL code, position, LOD score, Threshold, Genetic variance and effects of the QTLs detected, and position of the nearest SNP marker. Genetic Variance (VG) = Fraction of the total variation explained by the $Q T L, a=$ Additive effect. Dist= marker position on the genetic linkage map. Abbreviations: $R A C=$ Relative Antioxidant Capacity, RI=Ripening Index, SSC=Soluble Solids Concentration, $T A=T i t r a t a b l e ~ A c i d i t y$. See Table 1 for units. QTLs from multi-year analysis colored in gray: Genetic environmental interaction (VGE)= Fraction of the total variation explained by the genetic environmental interaction and marker ranges.

\begin{tabular}{|c|c|c|c|c|c|c|c|c|c|c|}
\hline Trait & QTL name & QTL code & $\mathbf{c M}$ & LOD score & Threshold & VG (\%) & VGE (\%) & $\begin{array}{l}\text { Additive } \\
\text { effect (a) }\end{array}$ & Flanking Markers & Dist cM \\
\hline \multirow[t]{6}{*}{ Production } & qPRD.V-Ch1_2-MYear & & 11.6 & & & 8.0 & 0.6 & 1.03 & SNP_IGA_22603-SNP_IGA_24260 & \\
\hline & qPRD.V-Ch3-Mean & PRD X-b & 9 & 3.34 & 2.13 & 16.3 & & 2.46 & SNP_IGA_308290 & 8.87 \\
\hline & qPRD.V-Ch3-MYear & & 14.3 & & & 8.6 & 0.3 & -1.00 & SNP_IGA_317404-SNP_IGA_319280 & \\
\hline & qPRD.V-Ch4-MYear & & 24,4 & & & 10.1 & 0.4 & -1.06 & SNP_IGA_389984-Pp17Cl & \\
\hline & qPRD.V-Ch8-2010 & PRD 10 & 13 & 2.90 & 2.14 & 17.0 & & 2.62 & SNP_IGA_841298 & 13.19 \\
\hline & qPRD.V-Ch8-Mean & PRD X-a & 24 & 3.74 & 2.13 & 18.1 & & 2.62 & SNP_IGA_862321 & 23.96 \\
\hline \multirow[t]{10}{*}{ Fruit weight } & qFW.V-Ch1_1-2010 & FW 10-c & 20 & 2.66 & 2.00 & 7.7 & & 30.28 & SNP_IGA_121534 & 19.64 \\
\hline & qFW.V-Ch4-2007 & FW 07 & 60 & 3.97 & 2.10 & 22.1 & & 39.21 & SNP_IGA_525520 & 59.11 \\
\hline & qFW.V-Ch4-2009 & FW 09 & 46 & 7.54 & 2.08 & 34.9 & & 42.53 & SNP_IGA_408981 & 45.50 \\
\hline & qFW.V-Ch4-2010 & FW 10-a & 47 & 17.97 & 2.00 & 50.1 & & 68.15 & SNP_IGA_408981 & 45.50 \\
\hline & qFW.V-Ch4-Mean & FW X-a & 46 & 17.38 & 2.13 & 54.7 & & 49.50 & SNP_IGA_408981 & 45.50 \\
\hline & qFW.V-Ch4-MYear & & 46.5 & & & 33.6 & 3.2 & -16.36 & SNP_IGA_408981-SNP_IGA_437516 & \\
\hline & qFW.V-Ch4-MYear & & 62.1 & & & 29.9 & 1.5 & -10.67 & SNP_IGA_5558633-SNP_IGA_467302 & \\
\hline & qFW.BT-Ch8-2010 & FW 10-b & 25 & 3.45 & 2.19 & 19.9 & & 40.81 & SNP_IGA_835981 & 31.76 \\
\hline & qFW.BT-Ch8-Mean & FW X-b & 9 & 3.07 & 2.21 & 15.3 & & 28.90 & ВРРС̄Т03̄ & 0.00 \\
\hline & qFW.BT-Ch8-MYear & & 16.0 & & & 11.6 & 2.0 & 16.80 & BPPCT033-SNP_IGA_835981 & \\
\hline \multirow[t]{8}{*}{ Firmness } & qFF.V-Ch4-2007 & FIR 07 & 48 & 8.37 & 2.33 & 43.2 & & 12.95 & SNP_IGA_408981 & 45.50 \\
\hline & qFF.V-Ch4-2009 & FIR 09-a & 55 & 3.37 & 2.12 & 19.5 & & 5.89 & SNP_IGA_440110 & 54.65 \\
\hline & qFF.V-Ch4-Mean & FIR X-a & 54 & 8.70 & 2.15 & 37.2 & & 6.59 & SNP_IGA_440110 & 54.65 \\
\hline & qFF.V-Ch4-MYear & & 48.5 & & & 18.3 & 12.0 & -3.28 & SNP_IGA_408981-SNP_IGA_437516 & \\
\hline & qFF.BT-Ch5-2009 & FIR 09-b & 12 & 4.74 & 2.21 & 24.9 & & 6.56 & SNP_IGA_555093 & 11.90 \\
\hline & qFF.BT-Ch5-2010 & FIR 10 & 3 & 3.42 & 2.17 & 19.9 & & 4.47 & SNP_IGA_544961 & 2.94 \\
\hline & qFF.BT-Ch5-Mean & FIR X-b & 12 & 2.27 & 2.23 & 14.6 & & 4.01 & SNP_IGA_585182 & 35.73 \\
\hline & qFF.BT-Ch5-MYear & & 10.9 & & & 7.0 & 2.3 & 1.90 & SNP_IGA_553456-SNP_IGA_555093 & \\
\hline \multirow[t]{8}{*}{ SSC } & qSSC.V-Ch2_2-2009 & SSC 09-d & 0 & 2.52 & 2.15 & 10.7 & & 1.34 & SNP_IGA_140938 & 0.00 \\
\hline & qSSC.V-Ch4-2007a & SSC 07-a & 29 & 3.45 & 2.06 & 18.5 & & -0.29 & SNP_IGA_399337 & 29.19 \\
\hline & qSSC.V-Ch4-2007b & SSC 07-b & 44 & 5.29 & 2.06 & 28.0 & & 0.99 & SNP_IGA_407115 & 44.03 \\
\hline & qSSC.V-Ch4-2009a & SSC 09-a & 32 & 2.61 & 2.15 & 11.3 & & 0.30 & SNP_IGA_400572 & 32.13 \\
\hline & qSSC.V-Ch4-2009b & SSC 09-b & 44 & 6.49 & 2.15 & 27.6 & & 1.57 & SNP_IGA_407115 & 44.03 \\
\hline & qSSC.V-Ch4-2010 & SSC $10-\mathrm{a}$ & 54 & 3.85 & 2.10 & 21.4 & & 1.78 & SNP_IGA_440110 & 54.65 \\
\hline & qSSC.V-Ch4-Mean & SSC X-a & 44 & 4.02 & 2.20 & 22.0 & & 1.37 & SNP_IGA_407115 & 44.03 \\
\hline & qSSC.V-Ch4-MYear & & 44.0 & & & 16.3 & 0.8 & -071 & SNP_IGA_407115-SNP_IGA_408981 & \\
\hline
\end{tabular}




\begin{tabular}{|c|c|c|c|c|c|c|c|c|c|c|}
\hline Trait & QTL name & QTL code & cM & LOD score & Threshold & VG (\%) & VGE (\%) & $\begin{array}{l}\text { Additive } \\
\text { effect (a) }\end{array}$ & Flanking Markers & Dist cM \\
\hline \multirow[t]{4}{*}{ SSC } & qSSC.BT-Ch5-2009 & SSC 09-c & 21 & 3.02 & 2.23 & 17.1 & & 1.48 & SNP_IGA_572589 & 24.39 \\
\hline & qSSC.BT-Ch5-2010 & SSC 10-b & 33 & 2.60 & 2.14 & 15.2 & & 1.18 & SNP_IGA_585182 & 35.73 \\
\hline & qSSC.BT-Ch5-Mean & SSC X-b & 29 & 2.32 & 2.18 & 13.5 & & 1.04 & SNP_IGA_572589 & 24.39 \\
\hline & qSSC.BT-Ch5-MYear & & 28.4 & & & 7.5 & 1.7 & 0.51 & SNP_IGA_572589-SNP_IGA_585182 & \\
\hline \multirow[t]{5}{*}{ pH } & qpH.BT-Ch5-2007 & pH 07 & 4 & 15.17 & 2.36 & 52.2 & & 0.40 & SNP_IGA_544961 & 2.94 \\
\hline & qpH.BT-Ch5-2009 & pH 09 & 3 & 27.96 & 2.48 & 85.3 & & 0.58 & SNP_IGA_544961 & 2.94 \\
\hline & qpH.BT-Ch5-2010 & pH 10 & 4 & 21.42 & 2.55 & 75.7 & & 0.53 & SNP_IGA_544961 & 2.94 \\
\hline & qpH.BT-Ch5-Mean & $\mathrm{pH} \mathrm{X}$ & 3 & 26.66 & 2.62 & 84.0 & & 0.51 & SNP_IGA_544961 & 2.94 \\
\hline & qpH.BT-Ch5-MYear & & 3.9 & & & 71.1 & 1.5 & 0.25 & SNP_IGA_544961-SNP_IGA_548597 & \\
\hline \multirow[t]{6}{*}{ TA } & qTA.BT-Ch5-2007 & TA 07-a & 3 & 12.67 & 2.63 & 60.4 & & 0.43 & SNP_IGA_544961 & 2.94 \\
\hline & qTA.BT-Ch5-2009 & TA 09 & 3 & 25.4 & 2.56 & 82.5 & & -0.37 & SNP_IGA_544961 & 2.94 \\
\hline & qTA.BT-Ch5-2010 & TA 10 & 2 & 14.8 & 2.54 & 62.6 & & -0.59 & SNP_IGA_544961 & 2.94 \\
\hline & qTA.BT-Ch5-Mean & TA X & 3 & 27.63 & 2.53 & 84.6 & & -0.46 & SNP_IGA_544961 & 2.94 \\
\hline & qTA.BT-Ch5MYear-a & & 2.9 & & & 62.9 & 0.2 & -0.23 & SNP_IGA_544961-SNP_IGA_548597 & \\
\hline & qTA.BT-Ch5MYear-b & & 53.7 & & & 0.9 & 2.7 & 0.01 & SNP_IGA_595212-SNP_IGA_597937 & \\
\hline \multirow[t]{5}{*}{ RI (SSC/TA) } & qRI.BT-Ch5-2007 & RI 07 & 0 & 7.55 & 2.45 & 42.4 & & 14.57 & SNP_IGA_543368 & 0.00 \\
\hline & qRI.BT-Ch5-2009 & RI 09 & 3 & 17.41 & 2.56 & 69.8 & & 17.06 & SNP_IGA_544961 & 2.94 \\
\hline & qRI.BT-Ch5-2010 & RI 10 & 4 & 11.38 & 2.54 & 53.1 & & 19.58 & SNP_IGA_548597 & 5.93 \\
\hline & qRI.BT-Ch5-Mean & RI X & 3 & 21.55 & 2.51 & 76.8 & & 17.52 & SNP_IGA_544961 & 2.94 \\
\hline & qRI.BT-Ch5-MYear & & 3.9 & & & 53.0 & 1.1 & 8.71 & SNP_IGA_544961-SNP_IGA_548597 & \\
\hline \multirow[t]{5}{*}{ Total sugars } & qTSU.V-Ch2_2-2009 & TSU 09-b & 0 & 2.52 & 2.14 & 15.5 & & 11.66 & SNP_IGA_140938 & 0.00 \\
\hline & qTSU.BT-Ch4-2010 & TSU 10 & 34 & 2.20 & 2.05 & 14.9 & & 15.20 & SNP_IGA_477941 & 33.97 \\
\hline & qTSU.BT-Ch5-2009 & TSU 09-c & 19 & 3.15 & 2.23 & 16.6 & & 12.01 & SNP_IGA_559057 & 14.84 \\
\hline & qTSU.BT-Ch5-Mean & TSU X-c & 23 & 2.43 & 2.01 & 15.1 & & 10.10 & SNP_IGA_572589 & 24.39 \\
\hline & qTSU.BT-Ch5-MYear & & 20.8 & & & 12.2 & 0.1 & 6.08 & SNP_IGA_559057-SNP_IGA_572589 & \\
\hline \multirow[t]{5}{*}{ Sucrose } & qSUC.V-Ch4-2010 & SUC 10 & 11 & 2.37 & 2.13 & 18.9 & & -11.73 & SNP_IGA_378159 & 11.02 \\
\hline & qSUC.BT-Ch5-2007 & SUC 07 & 5 & 2.87 & 2.16 & 18.6 & & -12.86 & SNP_IGA_548597 & 5.93 \\
\hline & qSUC.BT-Ch5-2009 & SUC 09 & 17 & 4.21 & 2.19 & 22.0 & & 10.89 & SNP_IGA_559057 & 14.84 \\
\hline & qSUC.BT-Ch5-Mean & SUC X & 3 & 6.14 & 2.13 & 30.4 & & 10.61 & SNP_IGA_544961 & 2.94 \\
\hline & qSUC.BT-Ch5-MYear & & 4.9 & & & 16.8 & 0.5 & 5.70 & SNP_IGA_544961-SNP_IGA_548597 & \\
\hline \multirow[t]{3}{*}{ Glucose } & qGLU.V-Ch4-2007 & GLU 07 & 48 & 4.07 & 2.06 & 23.8 & & 2.33 & SNP_IGA_408981 & 45.50 \\
\hline & qGLU.V-Ch4-MYear & & 47.5 & & & 9.0 & 6.0 & $-0-67$ & SNP_IGA_408981-SNP_IGA_437516 & \\
\hline & qGLU.BT-Ch3-MYear & & 26.5 & & & 5.4 & 2.0 & 0.50 & SNP_IGA_913739-SNP_IGA_346608 & \\
\hline
\end{tabular}




\begin{tabular}{|c|c|c|c|c|c|c|c|c|c|c|}
\hline Trait & QTL name & QTL code & $\mathbf{c M}$ & LOD score & Threshold & VG (\%) & VGE (\%) & $\begin{array}{l}\text { Additive } \\
\text { effect (a) }\end{array}$ & Flanking Markers & Dist cM \\
\hline \multirow[t]{8}{*}{ Sorbitol } & qSOR.V-Ch4-2007 & SOR 07 & 46 & 12.88 & 2.14 & 51.2 & & 4.50 & SNP_IGA_408981 & 45.50 \\
\hline & qSOR.V-Ch4-2008 & SOR 08 & 49 & 5.75 & 2.02 & 27.3 & & 4.35 & SNP_IGA_437516 & 51.66 \\
\hline & qSOR.V-Ch4-2009 & SOR 09 & 46 & 18.59 & 2.27 & 57.7 & & 6.48 & SNP_IGA_408981 & 45.50 \\
\hline & qSOR.V-Ch4-2010 & SOR 10a & 54 & 5.62 & 2.16 & 36.8 & & 3.82 & SNP_IGA_440110 & 54.65 \\
\hline & qSOR.V-Ch4- Mean & SOR X & 47 & 22.22 & 2.12 & 60.5 & & 4.71 & SNP_IGA_408981 & 45.50 \\
\hline & qSOR.V-Ch4- MYear & & 45.5 & & & 48.6 & 2.1 & -2.42 & SNP_IGA_408981-SNP_IGA_437516 & \\
\hline & qSOR.BT-Ch5-2010 & SOR 10b & 40 & 2.56 & 2.16 & 20.5 & & 2.72 & SNP_IGA586202 & 40.28 \\
\hline & qSOR.BT-Ch5-MYear & & 32.4 & & & 8.6 & 0.2 & 1.07 & SNP_IGA_572589-SNP_IGA_585182 & \\
\hline \multirow[t]{8}{*}{ Fructose } & qFRU.V-Ch2_1-2008 & FRU 08-a & 3 & 2.90 & 2.00 & 13.2 & & -2.13 & SNP_IGA_249781 & 0.00 \\
\hline & qFRU.V-Ch4-2007 & FRU 07-a & 48 & 2.73 & 2.14 & 17.6 & & 1.80 & SNP_IGA_408981 & 45.50 \\
\hline & qFRU.V-Ch4-MYear & & 47.5 & & & 6.0 & 2.8 & -0.56 & SNP_IGA_408981-SNP_IGA_437516 & \\
\hline & qFRU.BT-Ch1_2-2008 & FRU 08-b & 23 & 2.62 & 2.21 & 16.5 & & 2.27 & SNP_IGA_25403 & 23.04 \\
\hline & qFRU.BT-Ch1_2-Mean & FRU X-b & 23 & 2.48 & 2.26 & 15.9 & & 1.41 & SNP_IGA_25403 & 23.04 \\
\hline & qFRU.BT-Ch5-2007 & FRU 07-b & 54 & 3.57 & 2.28 & 22.7 & & 2.03 & SNP_IGA_595212 & 53.74 \\
\hline & qFRU.BT-Ch5-MYear & & 53.7 & & & 9.9 & 2.7 & 0.61 & SNP_IGA_595212-SNP_IGA_597937 & \\
\hline & qFRU.BT-Ch8-MYear & & 34.8 & & & 6.7 & 4.0 & 0.44 & SNP_IGA_835981-SNP_IGA_864110 & \\
\hline \multirow[t]{4}{*}{ Total Phenolics } & qPHE.V-Ch2_2-2009 & PHE 09-a & 0 & 2.32 & 2.16 & 14.3 & & 4.18 & SNP_IGA_140938 & 0.00 \\
\hline & qPHE.V-Ch4-Mean & PHE X & 45 & 2.67 & 2.18 & 15.8 & & 4.71 & SNP_IGA_408981 & 45.50 \\
\hline & qPHE.BT-Ch2-2009 & PHE 09-b & 1 & 2.50 & 2.21 & 15.0 & & -4.18 & SNP_IGA_141612 & 1.47 \\
\hline & qPHE.BT-Ch2-MYear & & 8.6 & & & 9.2 & 1.4 & -2.63 & SNP_IGA_230389-SNP_IGA_231766 & \\
\hline \multirow[t]{5}{*}{ Flavonoids } & qFLV.V-Ch2_2-2010 & FLV 10-a & 1.5 & 2.76 & 1.82 & 17.0 & & 4.59 & SNP_IGA_185060 & 1.47 \\
\hline & qFLV.V-Ch3-2008 & FLV 08-c & 3 & 2.18 & 2.02 & 10.1 & & -4.97 & SNP_IGA_298154 & 2.98 \\
\hline & qFLV.V-Ch4-2008 & FLV 08-a & 53 & 4.40 & 2.02 & 17.8 & & 7.22 & SNP_IGA_437516 & 51.66 \\
\hline & qFLV.V-Ch7-2008 & FLV 08-b & 0 & 4.04 & 2.02 & 18.6 & & -7.45 & SNP_IGA_787282 & 0.00 \\
\hline & qFLV.BT-Ch2-2010 & FLV 10-b & 0 & 2.86 & 1.93 & 17.1 & & -4.59 & SNP_IGA_161939 & 0.00 \\
\hline \multirow[t]{4}{*}{ Anthocyanins } & qANT.BT-Ch5-2009 & ANT 09 & 3 & 3.24 & 1.93 & 18.7 & & -3.84 & SNP_IGA_544961 & 2.94 \\
\hline & qANT.BT-Ch5-2010 & ANT 10 & 3 & 5.28 & 2.19 & 27.6 & & -4.15 & SNP_IGA_544961 & 2.94 \\
\hline & qANT.BT-Ch5-Mean & ANT X & 3 & 6.02 & 2.14 & 30.0 & & 1.98 & SNP_IGA_544961 & 2.94 \\
\hline & qANT.BT-Ch5-MYear & & 2.9 & & & 13.2 & 8.0 & -1.07 & SNP_IGA_544961-SNP_IGA_548597 & \\
\hline \multirow[t]{4}{*}{ RAC } & qRAC.V-Ch4-2009 & RAC 09-a & 46 & 7.47 & 2.14 & 34.9 & & 117.17 & SNP_IGA_408981 & 45.50 \\
\hline & qRAC.V-Ch4-Mean & RAC X & 54 & 3.58 & 2.03 & 20.2 & & 82.55 & SNP_IGA_440110 & 54.65 \\
\hline & qRAC.V-Ch4-MYear & & 45.0 & & & 11.6 & 6.0 & -26.80 & SNP_IGA_407115-SNP_IGA_408981 & \\
\hline & qRAC.BT-Ch8-2009 & RAC 09-b & 82 & 2.72 & 2.28 & 9.3 & & -59.61 & SNP_IGA_884538 & 81.39 \\
\hline
\end{tabular}




\section{Figures captions}

Fig. 1 Genetic linkage map of 'Venus'

Nine linkage groups of 'Venus'. In each linkage group names, 'V' refers to the 'Venus' parental, the first number to the scaffold that it represents and the second one to the subgroup when scaffold is represented by more than one linkage group. See the absence of scaffold 5 and the separation in two groups of scaffolds 1 and 2. SSR markers are in bold (UDP98-024 and UCDCH15 in V4; pchems5 and BPPCT025 in V6; and BINEPPCU6377 in V8), and the SNP_IGA_536394 in V6 is underlined

Fig. 2 Genetic linkage map of 'Big Top'

Ten linkage groups of 'Big Top'. In each linkage group, 'B' refers to the 'Big Top' parental, the first number to the scaffold that it represents and the second one to the subgroup when scaffold is represented by more than one linkage group. See the separation of scaffolds 1 and 6 in two linkage groups. SSR marker (BPPCT033) in B8 is in bold and markers (SNP_IGA_913769 in B3 and SNP_IGA_430365 in B7) are underlined

Fig. 3 QTL map of 'Venus'

Location of putative QTLs controlling fruit quality traits analyzed by year in 'Venus' map and determined by Single Regresion or MQM mapping. 'V' refers to the 'Venus' parental, the first number to the scaffold that it represents and second to the sub-group when scaffold is represented by more than one linkage group. Markers are listed at the right side of each LG and the genetic distances are listed at the left side. QTLs are drawn at the left of each corresponding LG and were represented in such a way that the thick line represents the inner confidence interval bound and the thin line represents the whole significance interval of the QTL. QTLs detected with the mean were not represented. The QTLs codes are described in Table 2 and Supplementary Table 4.

Fig. 4 QTL map of 'Big Top'

Location of putative QTLs controlling fruit quality traits analyzed by year in 'Big Top' map and determined by Single Regresion or MQM mapping. B' refers to the 'Big Top' parental, the first number to the scaffold that it represents and second to the sub-group when scaffold is represented by more than one linkage group. Markers are listed at the right side of each LG and the genetic distances are listed at the left side. QTLs are 
drawn at the left of each corresponding LG and were represented in such a way that the thick line represents the inner confidence interval bound and the thin line represents the whole significance interval of the QTL. QTLs detected with the mean were not represented. The QTLs codes are described in Table 2 and Supplementary Table 4. 


\section{Figure 1.}

V1_1

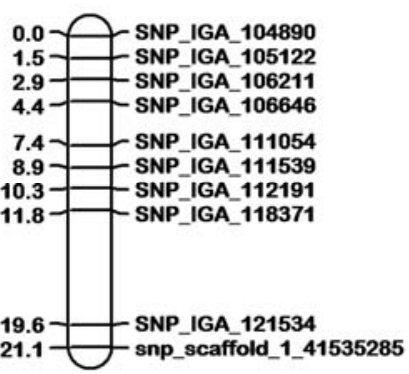

V1_2

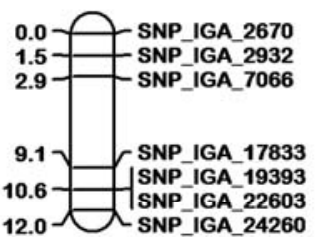

V6

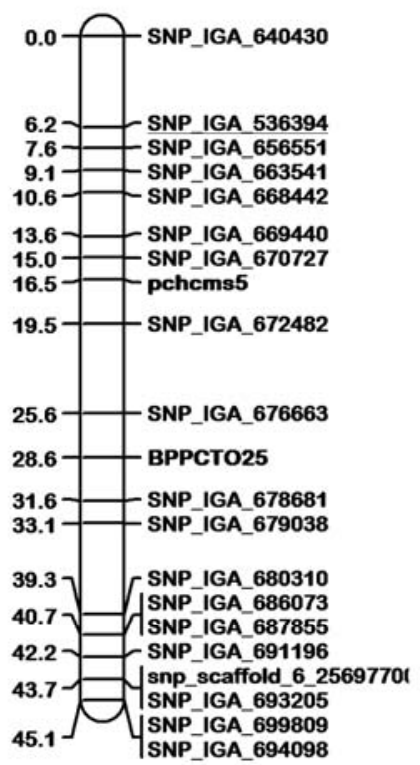

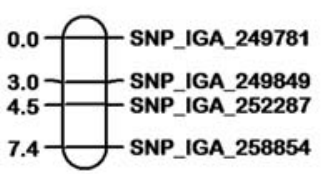

V2_2

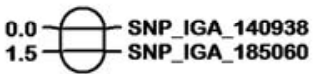

V7

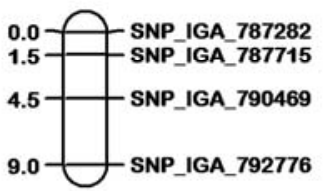

V8

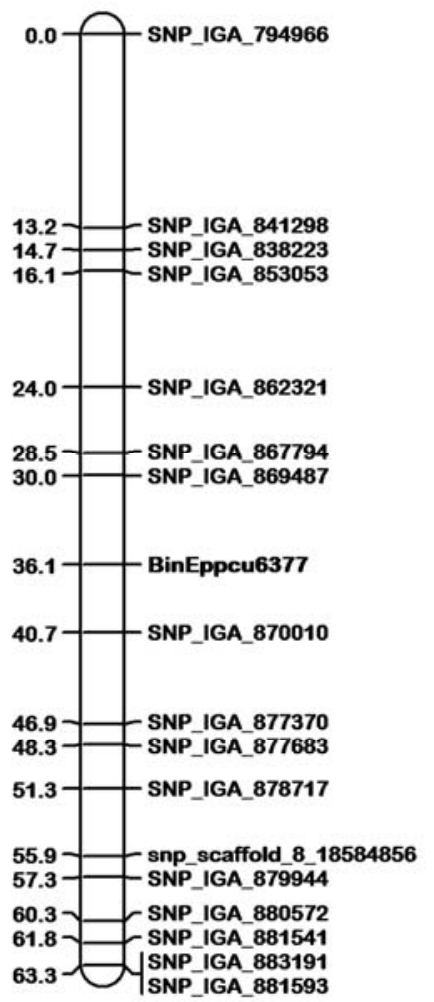

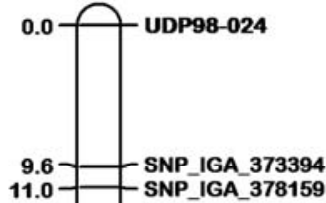

14.07

$15.5 \sqrt{\text { SNP_IGA_386222 }}$

$17.0-\square$ UCDCH15

SNP_IGA_387239

18.4- - SNP_IGA_389984

$27.7-$ SNP_IGA_398373

$29.2-$ SNP_IGA_399337

30.7- SNP_IGA_400440

33.6- SNP_IGA_401100

$36.6-$ SNP IGA 401886

38.1-— SNP_IGA_403152

44.0- SNP_IGA 407115

45.5- - SNPIGA 408981

\begin{tabular}{l|l}
$51.7-\longrightarrow$ SNP IGA 437516 \\
\hline
\end{tabular}

54.7- SNP IGA 447642

$57.6-\quad$ SNP IGA 52498

59.1- - SNP_IGA_525520

62.1- - SNP_IGA_525863
32.1- SNP_IGA 40057

41.0 - - SNP_IGA_405949

$85.7-$ SNP_IGA_467302
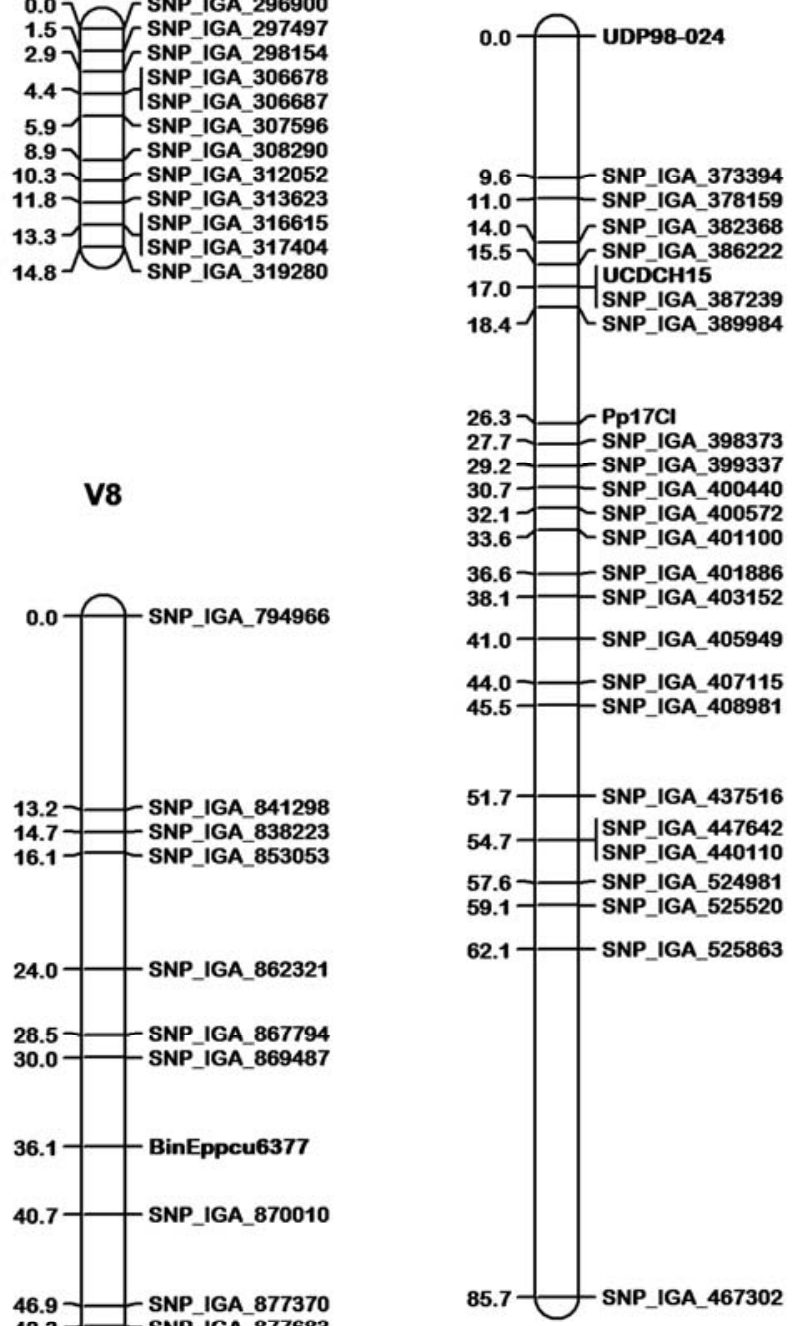
Figure 2.

B1_1

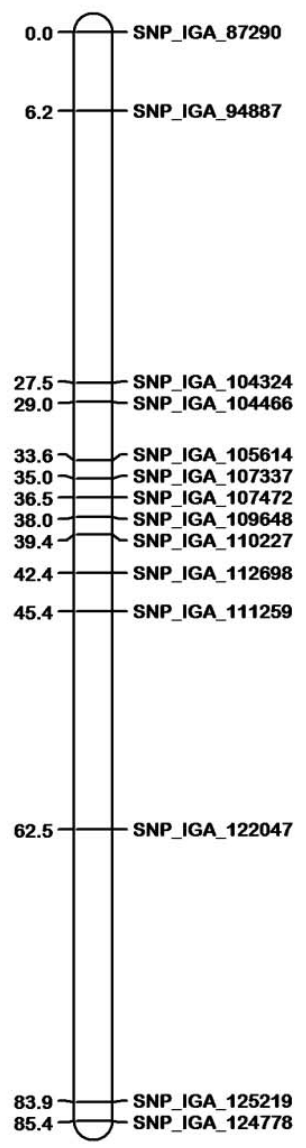

B1_2

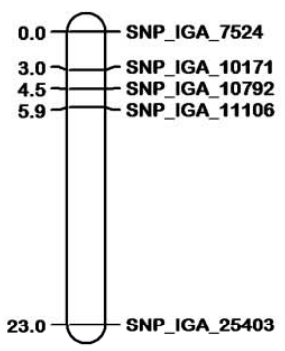

B2

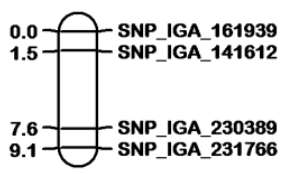

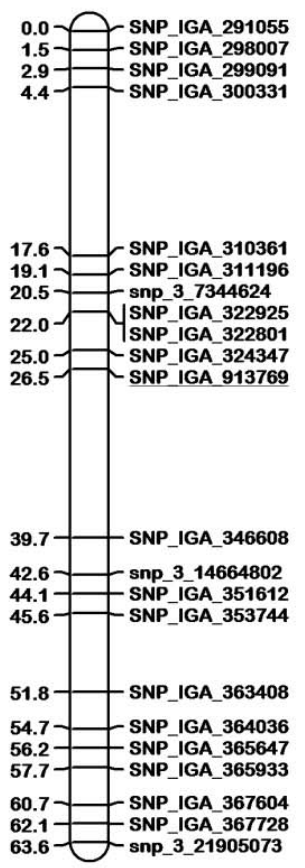
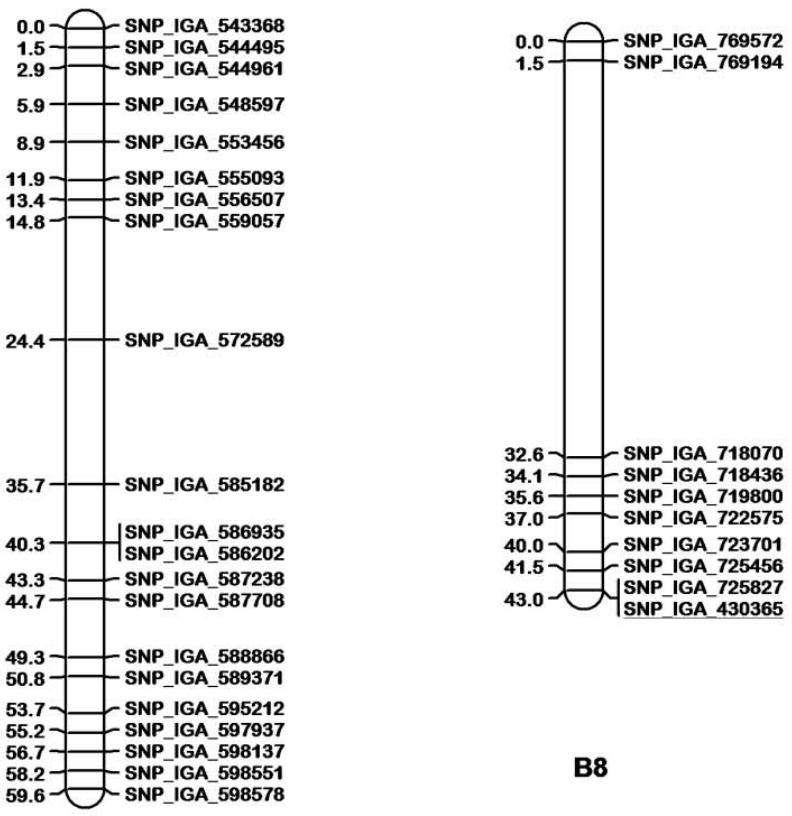

B6_1

B4

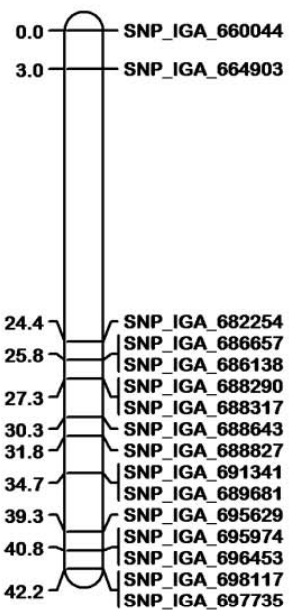

B6_2

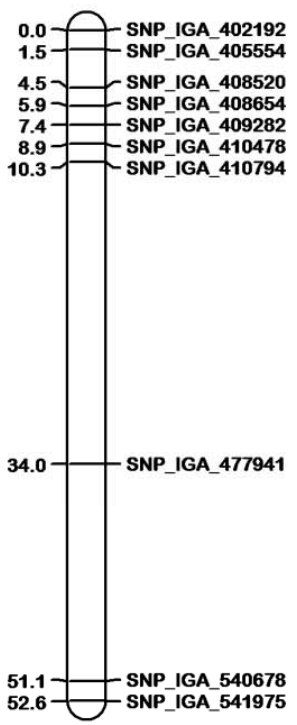

1.5- $\bigcirc$ SNP_IGA_614024
B8

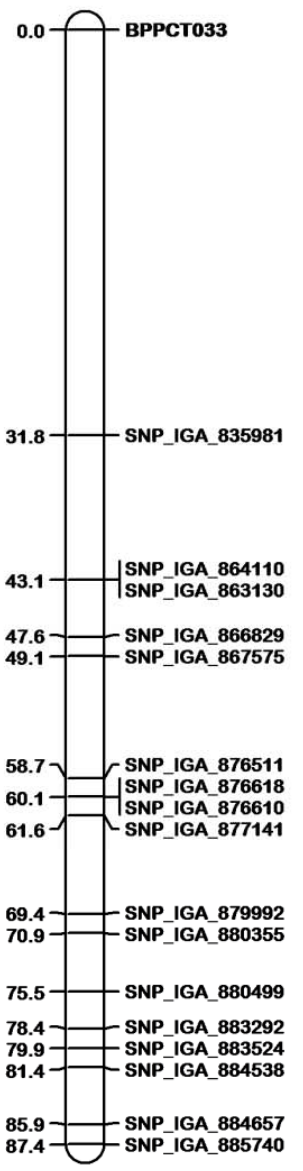




\section{Figure 3.}

V1_1

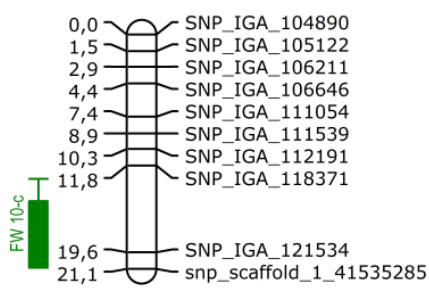

V2_1

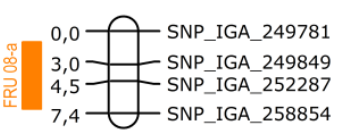

V2_2

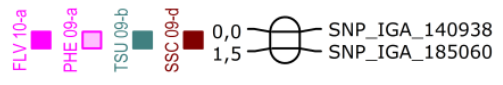

\section{V3}

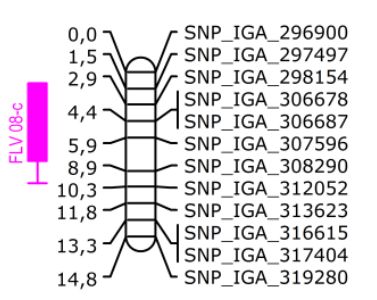

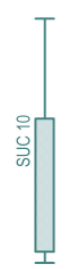

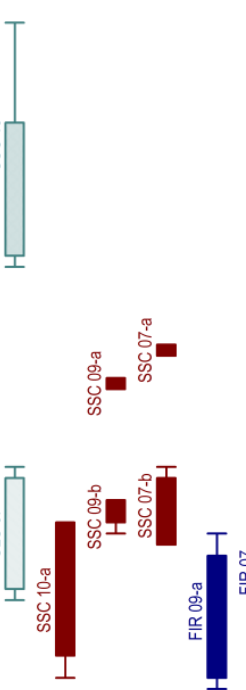

v7
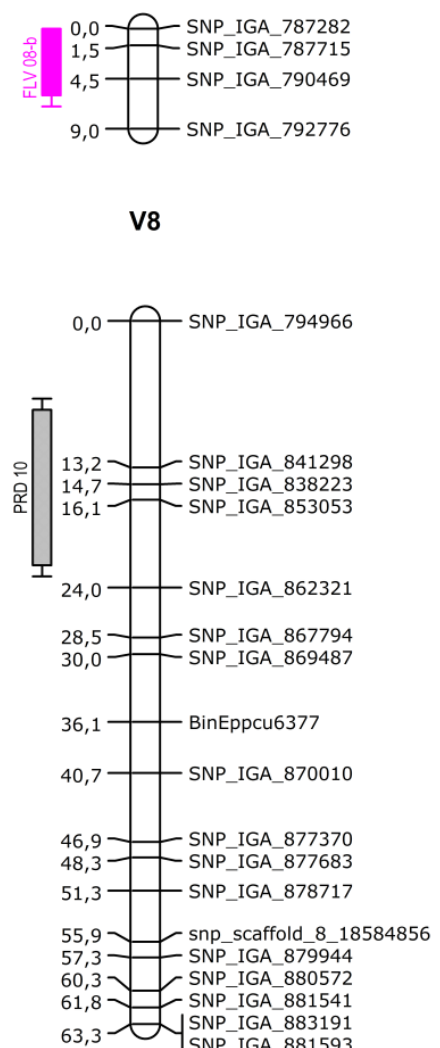
Figure 4.

B1_2

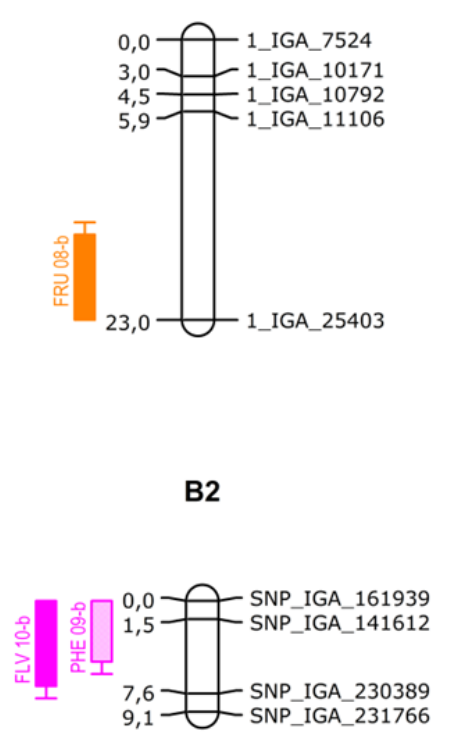

B4

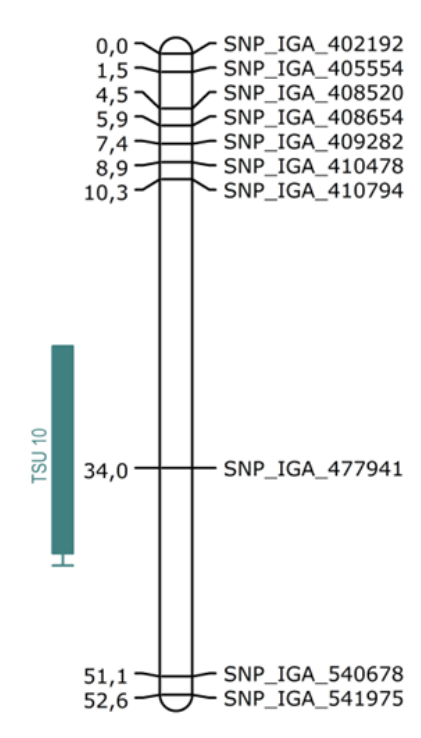

B5

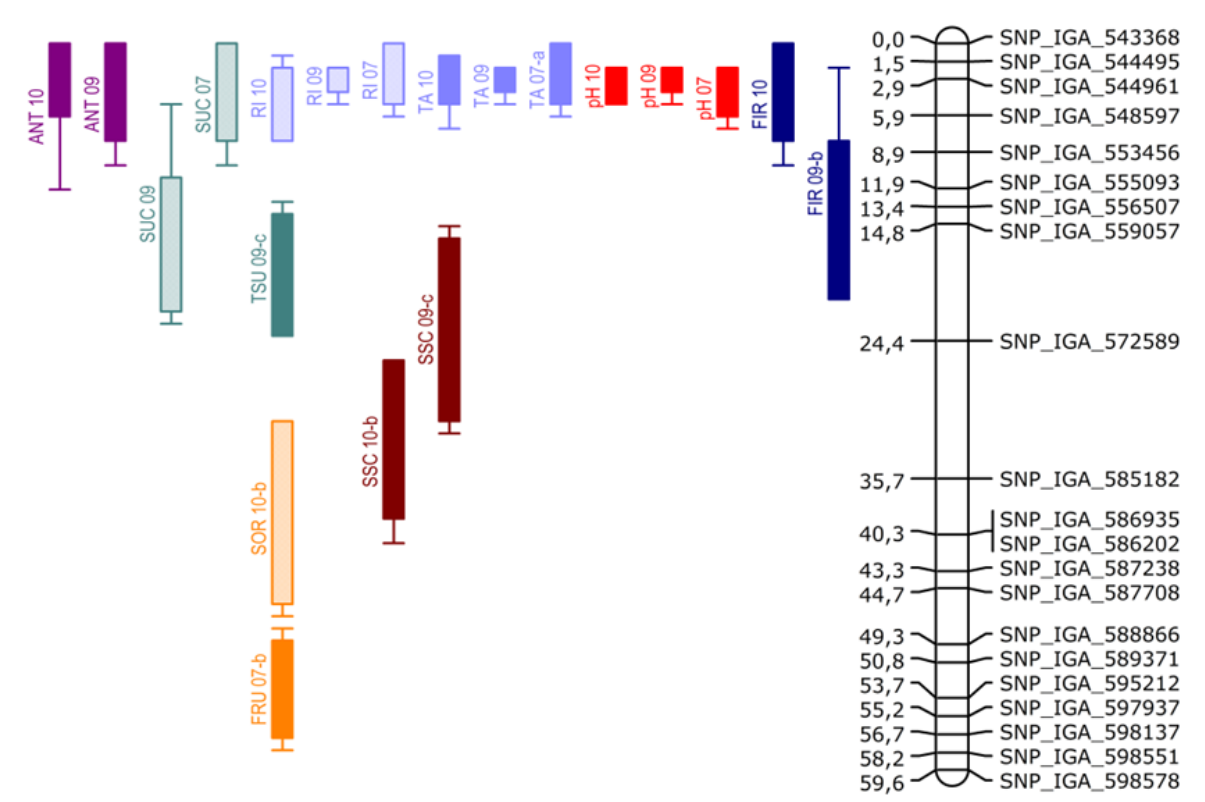

B8

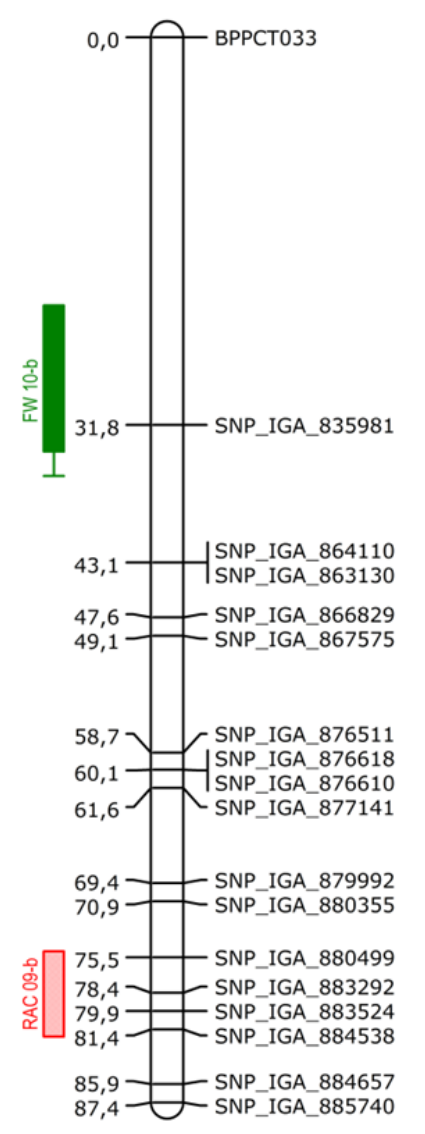


Supplementary Fig. 1. Distribution of phenotypic data in the population during four seasons (2007-2010).
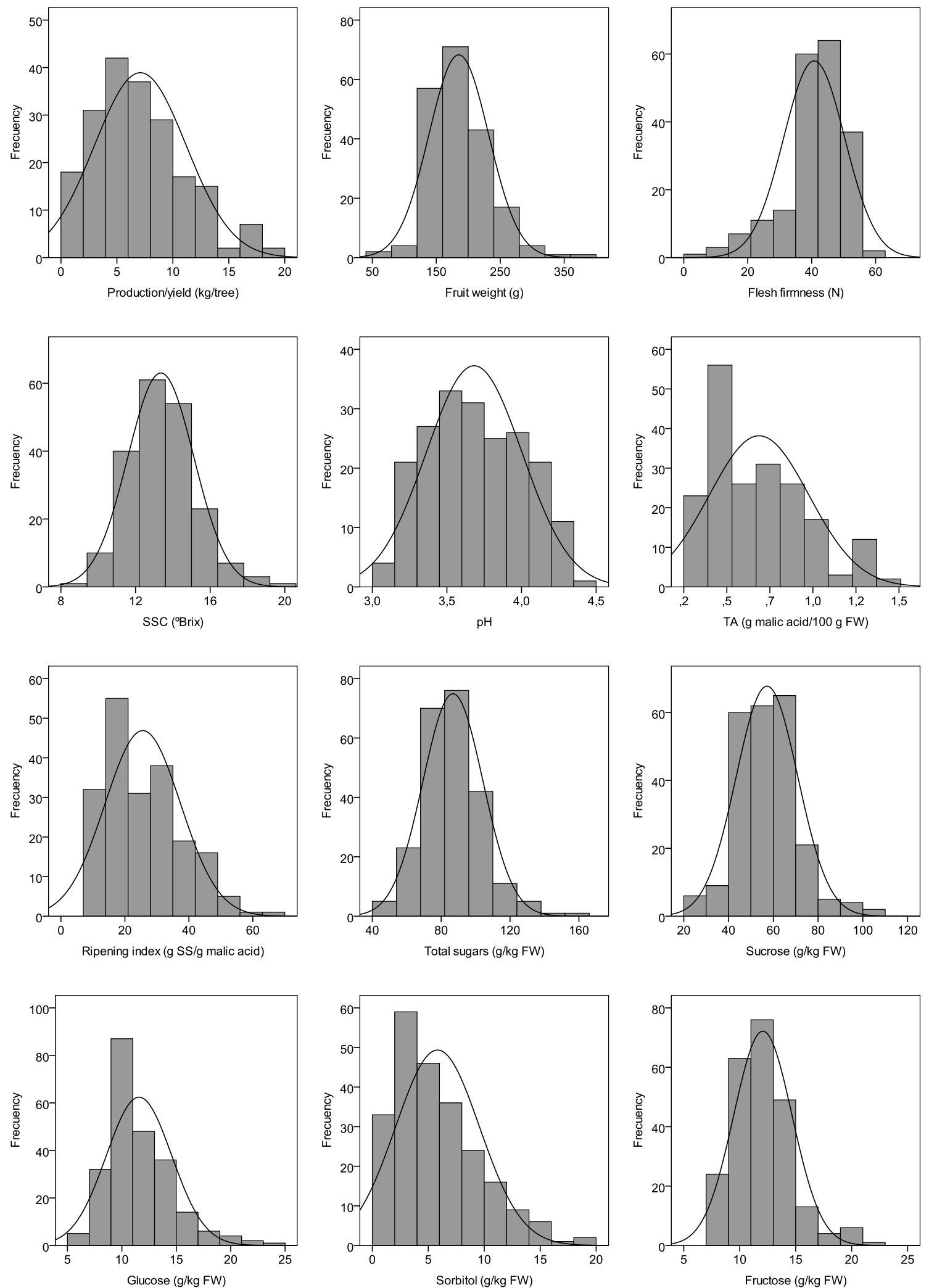
Supplementary Fig. 1 (continued)
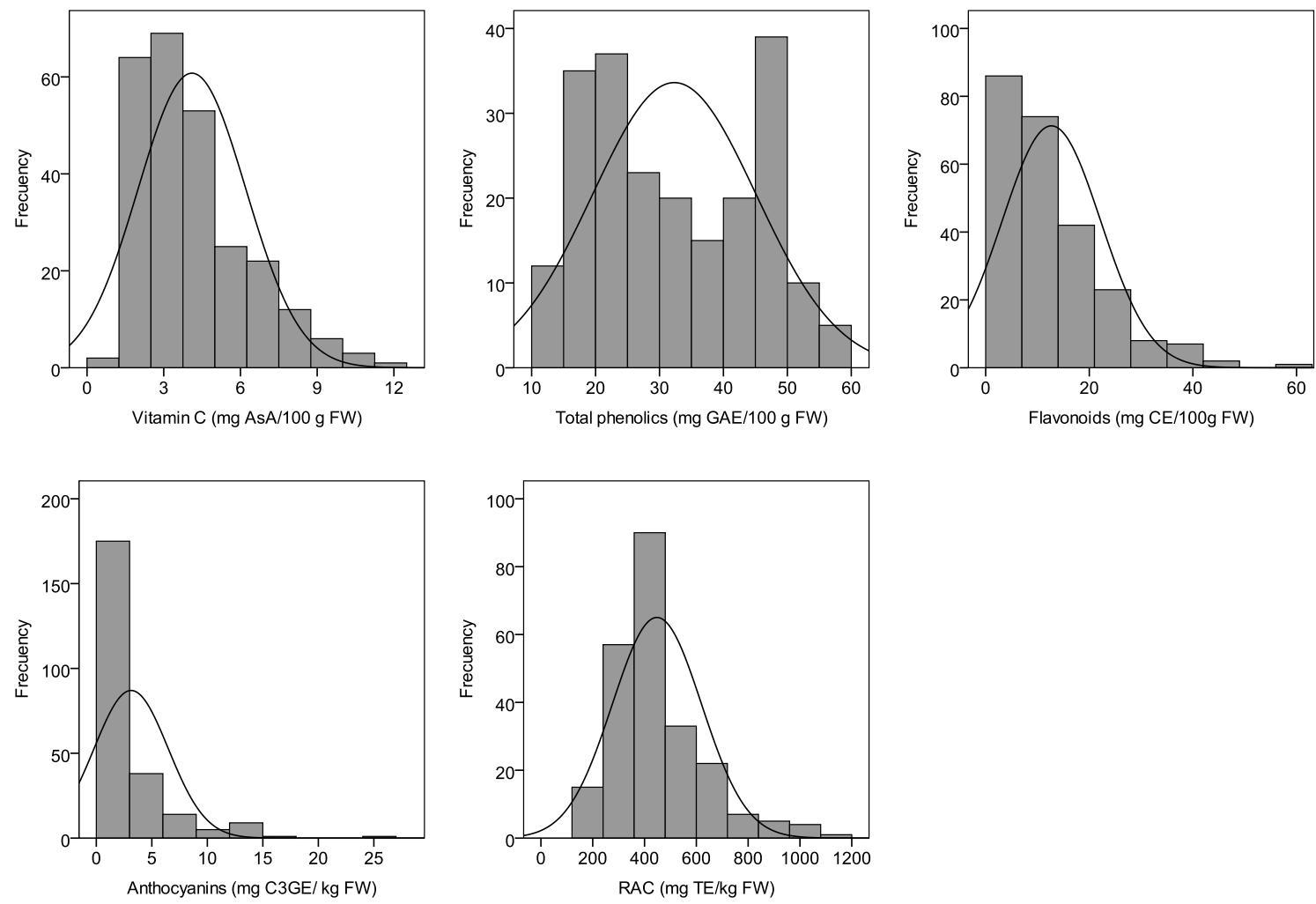
Supplementary Table 1. Pearson's correlation coefficients for pomological traits 2007, 2008, 2009 and 2010 using all individuals evaluated each year.

\begin{tabular}{|c|c|c|c|c|}
\hline Traits & Year & 2008 & 2009 & 2010 \\
\hline \multirow[t]{2}{*}{ Production /yield } & 2007 & & $0.593^{* *}$ & $0.674^{* *}$ \\
\hline & 2009 & & & $0.484^{* *}$ \\
\hline \multirow[t]{2}{*}{ Fruit weight } & 2007 & & $0.443^{* *}$ & $0.276^{*}$ \\
\hline & 2009 & & & $0.85^{* *}$ \\
\hline \multirow[t]{2}{*}{ Firmness } & 2007 & & $0.287^{*}$ & 0.189 \\
\hline & 2009 & & & $0.392^{* *}$ \\
\hline \multirow[t]{2}{*}{ SSC } & 2007 & & 0.236 & $0.321^{* *}$ \\
\hline & 2009 & & & $0.476^{* *}$ \\
\hline \multirow[t]{2}{*}{ pH } & 2007 & & $0.742^{* *}$ & $0.680^{* * *}$ \\
\hline & 2009 & & & $0.862^{* *}$ \\
\hline \multirow[t]{2}{*}{ TA } & 2007 & & $0.740^{* * *}$ & $0.513^{* * *}$ \\
\hline & 2009 & & & $0.776^{* *}$ \\
\hline \multirow[t]{2}{*}{$\mathbf{R I}$} & 2007 & & $0.566^{* *}$ & $0.435^{* *}$ \\
\hline & 2009 & & & $0.642^{* *}$ \\
\hline \multirow[t]{3}{*}{ Total sugars } & 2007 & 0.191 & 0.248 & 0.127 \\
\hline & 2008 & & 0.041 & $0.362^{*}$ \\
\hline & 2009 & & & 0.170 \\
\hline \multirow[t]{3}{*}{ Sucrose } & 2007 & 0.078 & 0.223 & 0.117 \\
\hline & 2008 & & 0.016 & 0.173 \\
\hline & 2009 & & & 0.047 \\
\hline \multirow[t]{3}{*}{ Glucose } & 2007 & $0.383^{* *}$ & $0.330^{*}$ & 0.191 \\
\hline & 2008 & & $0.311^{*}$ & 0.213 \\
\hline & 2009 & & & 0.129 \\
\hline \multirow[t]{3}{*}{ Sorbitol } & 2007 & $0.506^{* *}$ & $0.649^{* *}$ & $0.456^{* *}$ \\
\hline & 2008 & & $0.411^{* * *}$ & $0.346^{*}$ \\
\hline & 2009 & & & $0.484^{* *}$ \\
\hline \multirow[t]{3}{*}{ Fructose } & 2007 & $0.472^{* *}$ & $0.342^{* *}$ & 0.277 \\
\hline & 2008 & & $0.397^{* *}$ & $0.301^{*}$ \\
\hline & 2009 & & & 0.130 \\
\hline \multirow[t]{3}{*}{ Vitamin C } & 2007 & 0.082 & 0.065 & -0.064 \\
\hline & 2008 & & 0.049 & 0.182 \\
\hline & 2009 & & & 0.073 \\
\hline \multirow[t]{3}{*}{ Total phenolics } & 2007 & 0.073 & 0.138 & 0.116 \\
\hline & 2008 & & 0.185 & 0.299 \\
\hline & 2009 & & & $0.467^{\star *}$ \\
\hline \multirow[t]{3}{*}{ Flavonoids } & 2007 & -0.145 & 0.128 & -0.016 \\
\hline & 2008 & & 0.246 & $0.549^{* *}$ \\
\hline & 2009 & & & $0.417^{* *}$ \\
\hline \multirow[t]{3}{*}{ Anthocyanins } & 2007 & 0.083 & -0.110 & 0.079 \\
\hline & 2008 & & -0.119 & 0.004 \\
\hline & 2009 & & & $0.430^{\star *}$ \\
\hline \multirow[t]{3}{*}{ RAC } & 2007 & 0.100 & 0.063 & 0.072 \\
\hline & 2008 & & 0.211 & $0.620^{* *}$ \\
\hline & 2009 & & & $0.354^{\star *}$ \\
\hline
\end{tabular}

${ }^{\star} P<0.05 ;{ }^{* \star} P<0.01$; Others not significant. 
Supplementary Table 2. Pearson's correlation coefficients between the pomological traits evaluated in the 'Venus' $\times$ 'Big Top' progeny during four years (2007-2010).

\begin{tabular}{|c|c|c|c|c|c|c|c|c|c|c|c|c|c|c|c|c|}
\hline & $\begin{array}{l}\text { Fruit } \\
\text { weight }\end{array}$ & Firmness & SSC & pH & TA & RI & $\begin{array}{l}\text { Total } \\
\text { sugars }\end{array}$ & Sucrose & Glucose & Sorbitol & Fructose & Vitamin $\mathbf{C}$ & $\begin{array}{l}\text { Total } \\
\text { phenolics }\end{array}$ & Flavonoids & Anthocyanins & RAC \\
\hline Production/yield & 0.019 & -0.110 & -0.242 & 0.002 & 0.043 & $-0.188^{* *}$ & $-0.282^{* *}$ & $-0.246 * *$ & -0.112 & -0.143 & $-0.161 *$ & -0.001 & -0.081 & $-0.152 *$ & $-0.157^{*}$ & $-0.200 * *$ \\
\hline Fruit weight & 1.00 & $0.310^{* *}$ & $0.197 * *$ & 0.023 & -0.030 & 0.095 & 0.091 & 0.049 & -0.116 & $0.351 * *$ & -0.090 & -0.095 & $-0.176^{*}$ & -0.146 & 0.082 & $0.391 * *$ \\
\hline Firmness & & 1.00 & $0.181 *$ & $0.268^{* * *}$ & -0.134 & $0.202^{* *}$ & $0.285 * *$ & 0.139 & $0.280^{* * *}$ & $0.414 * *$ & $0.330^{* *}$ & $0.219 * *$ & $-0.502 * *$ & $-0.407 * *$ & -0.003 & 0.134 \\
\hline SSC & & & 1.00 & $0.163^{*}$ & -0.121 & $0.368^{* *}$ & $0.670^{* *}$ & $0.523 * *$ & $0.315^{* * *}$ & $0.633 * *$ & $0.338^{* *}$ & $0.405^{* *}$ & $0.231 *$ & $0.266^{* *}$ & -0.080 & $0.371 * *$ \\
\hline pH & & & & 1.00 & $-0.804 * *$ & $0.799 * *$ & $0.304 * *$ & $0.404 * *$ & $-0.172 *$ & 0.140 & -0.088 & $0.243 * *$ & $-0.195^{*}$ & $-0.177 *$ & $-0.260^{* *}$ & $-0.199 *$ \\
\hline TA & & & & & 1.00 & $-0.869 * *$ & -0.260 ** & $-0.360^{* * *}$ & $0.198^{* * *}$ & -0.110 & 0.125 & -0.054 & -0.025 & -0.012 & $0.307 * *$ & 0.060 \\
\hline RI & & & & & & 1.00 & 0.379 ** & $0.461 * *$ & -0.141 & $0.205^{* *}$ & -0.088 & 0.065 & 0.010 & 0.009 & $-0.235^{* *}$ & 0.052 \\
\hline Total sugars & & & & & & & 1.00 & $0.910^{* *}$ & $0.356^{* *}$ & $0.658 * *$ & $0.658^{* * *}$ & $0.463 * *$ & 0.129 & $0.156^{*}$ & -0.051 & $0.151 *$ \\
\hline Sucrose & & & & & & & & 1.00 & 0.013 & $0.453 * *$ & 0.026 & $0.384 * *$ & 0.022 & -0.020 & -0.020 & -0.057 \\
\hline Glucose & & & & & & & & & 1.00 & $0.190 * *$ & $0.799 * *$ & 0.122 & $0.366^{* *}$ & $0.493 * *$ & $-0.161^{*}$ & $0.515^{* *}$ \\
\hline Sorbitol & & & & & & & & & & 1.00 & 0.179 ** & $0.388 * *$ & 0.044 & 0.041 & -0.031 & 0.097 \\
\hline Fructose & & & & & & & & & & & 1.00 & $0.165 * *$ & $0.256^{* *}$ & $0.415^{* *}$ & $-0.136^{*}$ & $0.443 * *$ \\
\hline Vitamin C & & & & & & & & & & & & 1.00 & $-0.204^{* *}$ & -0.003 & $0.189 * *$ & -0.022 \\
\hline Total phenolics & & & & & & & & & & & & & 1.00 & $0.828 * *$ & $-0.329^{* *}$ & $0.632 * *$ \\
\hline Flavonoids & & & & & & & & & & & & & & 1.00 & $-0.186 * *$ & $0.761^{* *}$ \\
\hline Anthocyanins & & & & & & & & & & & & & & & 1.00 & $-0.184 * *$ \\
\hline RAC & & & & & & & & & & & & & & & & 1.00 \\
\hline
\end{tabular}

$* P<0.05 ; * * P<0.01$; Others not significant. 
Supplementary Table 3. List of the SNPs mapped in the ‘Venus' × ‘Big Top’ population and its physical position in Peach genome v1.0 and v2.0.

\begin{tabular}{|c|c|c|}
\hline Scaffold 1 & Peach v1 & Peach v2 \\
\hline SNP_IGA_2670 & scaffold_1:894,161 & Рp01:894020 \\
\hline SNP_IGA_2932 & scaffold_1:948,556 & Pp01:948415 \\
\hline SNP_IGA_7066 & scaffold_1:2,195,186 & Pp01:2194983 \\
\hline SNP_IGA_7524 & scaffold_1:2,335,269 & Pp01:2335065 \\
\hline SNP_IGA_10171 & scaffold_1:3,319,106 & Рp01:3318869 \\
\hline SNP_IGA_10792 & scaffold_1:3,563,709 & Рp01:3563475 \\
\hline SNP_IGA_11106 & scaffold_1:3,660,651 & Pp01:3660418 \\
\hline SNP_IGA_17833 & scaffold_1:5,803,431 & Рp01:6252790 \\
\hline SNP_IGA_19393 & scaffold_1:6,411,736 & Pp01:6861098 \\
\hline SNP_IGA_22603 & scaffold_1:7,500,056 & Pp01:7949418 \\
\hline SNP_IGA_24260 & scaffold_1:8,357,315 & Pp01:8806675 \\
\hline SNP_IGA_25403 & scaffold_1:8,812,754 & Pр01:9262114 \\
\hline SNP_IGA_87290 & scaffold_1:25,762,314 & Рp01:26736917 \\
\hline SNP_IGA_94887 & scaffold_1:28,142,364 & Pp01:29116355 \\
\hline SNP_IGA_104324 & scaffold_1:33,105,631 & Рp01:34079472 \\
\hline SNP_IGA_104466 & scaffold_1:33,154,340 & Pp01:34128181 \\
\hline SNP_IGA_104890 & scaffold_1:33,430,259 & Pp01:34404100 \\
\hline SNP_IGA_105122 & scaffold_1:33,489,785 & Pp01:34463626 \\
\hline SNP_IGA_105614 & scaffold_1:33,659,804 & Pp01:34633645 \\
\hline SNP_IGA_106211 & scaffold_1:33,935,933 & Рp01:34909774 \\
\hline SNP_IGA_106646 & scaffold_1:34,095,609 & Рp01:35069450 \\
\hline SNP_IGA_107337 & scaffold_1:34,358,459 & Pp01:35332300 \\
\hline SNP_IGA_107472 & scaffold_1:34,496,362 & Рp01:35469583 \\
\hline SNP_IGA_109648 & scaffold_1:35,351,837 & Рp01:36325047 \\
\hline SNP_IGA_110227 & scaffold_1:35,577,807 & Pp01:36551019 \\
\hline SNP_IGA_111054 & scaffold_1:35,832,121 & Pp01:36805333 \\
\hline SNP_IGA_111259 & scaffold_1:36,067,680 & Рp01:37040892 \\
\hline SNP_IGA_111539 & scaffold_1:36,269,360 & Рp01:37242573 \\
\hline SNP_IGA_112191 & scaffold_1:36,617,840 & Pp01:37591210 \\
\hline SNP_IGA_112698 & scaffold_1:36,761,277 & Pp01:37734647 \\
\hline SNP_IGA_118371 & scaffold_1:39,205,411 & Pр01:40178780 \\
\hline SNP_IGA_121534 & scaffold_1:40,713,626 & Pp01:41686892 \\
\hline SNP_IGA_122047 & scaffold_1:41,007,523 & Pp01:41980790 \\
\hline snp_scaffold_1_41535285 & scaffold_1:41,535,285 & Pp01:42508498 \\
\hline SNP_IGA_124778 & scaffold_1:42,628,464 & Рp01:47187541 \\
\hline SNP_IGA_125219 & scaffold_1:42,831,911 & Рp01:46984218 \\
\hline
\end{tabular}

\begin{tabular}{lll}
\hline Scaffold 2 & Peach v1 & Peach v2 \\
\hline SNP_IGA_140938 & scaffold_2:778744 & Pp02:2524809 \\
SNP_IGA_141612 & scaffold_2:881016 & Pp02:2627082 \\
SNP_IGA_161939 & scaffold_2:2478864 & Pp02:4224893 \\
SNP_IGA_185060 & scaffold_2:4006746 & Pp02:5751793 \\
SNP_IGA_230389 & scaffold_2:9280916 & Pp02:1338721 \\
SNP_IGA_231766 & scaffold_2:9415276 & Pp02:1204461 \\
SNP_IGA_249781 & scaffold_2:12440279 & Pp02:15218516 \\
SNP_IGA_249849 & scaffold_2:12464202 & Pp02:15242439 \\
SNP_IGA_252287 & scaffol__2:13006417 & Pp02:15784654 \\
SNP_IGA_258854 & scaffold_2:14440907 & Pp02:17219077
\end{tabular}

\begin{tabular}{lll}
\hline Scaffold 3 & Peach v1 & Peach v2 \\
\hline SNP_IGA_291055 & scaffold_3:67897 & Pp03:929735 \\
SNP_IGA_296900 & scaffold_3:2528714 & Pp03:3390662 \\
SNP_IGA_297497 & scaffold_3:2774393 & Pp03:3635392 \\
SNP_IGA_298007 & scaffold_3:2988044 & Pp03:3849042 \\
SNP_IGA_298154 & scaffold_3:30349775 & Pp03:3895956. \\
SNP_IGA_299091 & scaffold_3:3163382 & Pp03:4024362
\end{tabular}

\begin{tabular}{lll}
\hline Scaffold 4 & Peach v1 & Peach v2 \\
\hline SNP_IGA_373394 & scaffold_4:865720 & Pp04:865823..
\end{tabular}

SNP_IGA_378159 Scaffold_4:1320979 Pp04:1321081

SNP_IGA_382368 Scaffold_4:2689227 Pp04:2689336

$\begin{array}{lll}\text { SNP_IGA_382368 } & \text { scaffold_4:2689227 } & \text { Pp04:2689336 } \\ \text { SNP_IGA_386222 } & \text { scaffold_4:4045369 } & \text { Pp04:4045426 }\end{array}$

SNP_IGA_387239 Scaffold_4:4533189 Pp04:4533174

SNP_IGA_389984 scaffold_4:5021007 Pp04:5020995

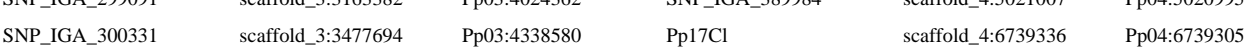

SNP_IGA_306678 $\quad$ scaffold_3:4819681 $\quad$ Pp03:5680211 $\quad$ SNP_IGA_398373 $\quad$ scaffold_4:6934721 $\quad$ Pp04:6934689

SNP_IGA_306687 $\quad$ scaffold_3:4821129 $\quad$ Pp03:5681659 $\quad$ SNP_IGA_399337 $\quad$ scaffold_4:7090751 $\quad$ Pp04:7090720

$\begin{array}{llllll}\text { SNP_IGA_307596 } & \text { scaffold_3:5061446 } & \text { Pp03:5921975 } & \text { SNP_IGA_400440 } & \text { scaffold_4:7275570 } & \text { Pp04:7275539 }\end{array}$

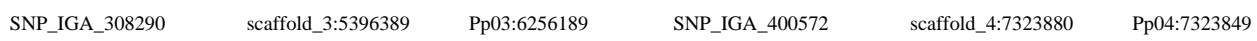

SNP_IGA_310361 $\quad$ scaffold_3:5894946 $\quad$ Pp03:6754745 $\quad$ SNP_IGA_401100 $\quad$ scaffold_4:7541219 $\quad$ Pp04:7541276

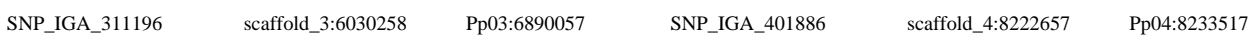

$\begin{array}{llllll}\text { SNP_IGA_312052 } & \text { scaffold_3:6228215 } & \text { Pp03:7088012 } & \text { SNP_IGA_402192 } & \text { scaffold_4:8341151 } & \text { Pp04:8352011 }\end{array}$

$\begin{array}{llllll}\text { SNP_IGA_313623 } & \text { scaffold_3:6546629 } & \text { Pp03:7406427 } & \text { SNP_IGA_403152 } & \text { scaffold_4:8966988 } & \text { Pp04:8977975 }\end{array}$

SNP_IGA_316615 $\quad$ scaffold_3:7285845 $\quad$ Pp03:8145641 $\quad$ SNP_IGA_405554 $\quad$ scaffold_4:9606600 $\quad$ Pp04:9617585

$\begin{array}{llllll}\text { snp_3_7344624 } & \text { scaffold_3:7344624 } & \text { Pp03:8204420 } & \text { SNP_IGA_405949 } & \text { scaffold_4:9690588 } & \text { Pp04:9701574 }\end{array}$

SNP_IGA_317404 $\quad$ scaffold_3:7421669 $\quad$ Pp03:8281465 $\quad$ SNP_IGA_407115 $\quad$ scaffold_4:9936483 $\quad$ Pp04:9947470

$\begin{array}{llllll}\text { SNP_IGA_319280 } & \text { scaffold_3:7855057 } & \text { Pp03:8714889 } & \text { SNP_IGA_408520 } & \text { scaffold_4:1018305 } & \text { Pp04:10194038 }\end{array}$

SNP_IGA_322801 $\quad$ scaffold_3:9057222 $\quad$ Pp03:9916964 $\quad$ SNP_IGA_408654 $\quad$ scaffold_4:10203034 $\quad$ Pp04:10214022

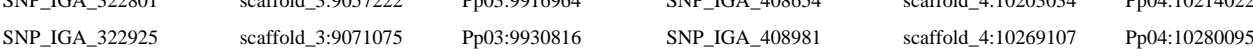

$\begin{array}{llllll}\text { SNP_IGA_324347 } & \text { scaffold_3:9363762 } & \text { Pp03:10223404 } & \text { SNP_IGA_409282 } & \text { scaffold_4:10373637 } & \text { Pp04:10384625 }\end{array}$

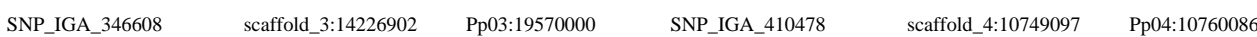

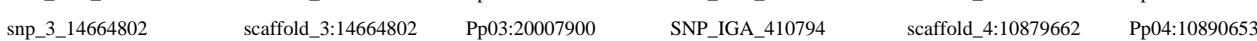

SNP_IGA_351612 $\quad$ scaffold_3:15617364 $\quad$ Pp03:20960378 $\quad$ SNP_IGA_430365 $\quad$ scaffold_4:15542419 $\quad$ Pp03:1141328

$\begin{array}{llllll}\text { SNP_IGA_353744 } & \text { scaffold_3:16355753 } & \text { Pp03:21698237 } & \text { SNP_IGA_437516 } & \text { scaffold_4:17094116 } & \text { Pp04:15182577 }\end{array}$

$\begin{array}{llllll}\text { SNP_IGA_363408 } & \text { scaffold_3:19666648 } & \text { Pp03:25009525 } & \text { SNP_IGA_440110 } & \text { scaffold_4:17988261 } & \text { Pp04:16076720 }\end{array}$

$\begin{array}{llllll}\text { SNP_IGA_364036 } & \text { scaffold_3:19916263 } & \text { Pp03:25258726 } & \text { SNP_IGA_447642 } & \text { scaffold_4:19688796 } & \text { Pp04:17777038 }\end{array}$

SNP_IGA_365647 $\quad$ scaffold_3:20537330 $\quad$ Pp03:25879794 $\quad$ SNP_IGA_467302 $\quad \begin{array}{lll}\text { scaffold_4:22631600 } & \text { Pp04:19028425 }\end{array}$

$\begin{array}{llllll}\text { SNP_IGA_365933 } & \text { scaffol__3:20719430 } & \text { Pp03:26061895 } & \text { SNP_IGA_477941 } & \text { scaffold_4:23497381 } & \text { Pp04:19894211 }\end{array}$

$\begin{array}{llllll}\text { SNP_IGA_367604 } & \text { scaffol__3:21686505 } & \text { Pp03:27028967 } & \text { SNP_IGA_524981 } & \text { scaffold_4:27077999 } & \text { Pp04:23475348 }\end{array}$

$\begin{array}{llllll}\text { SNP_IGA_367728 } & \text { scaffold_3:21798019 } & \text { Pp03:27140481 } & \text { SNP_IGA_525520 } & \text { scaffold_4:27189300 } & \text { Pp04:23586650 }\end{array}$

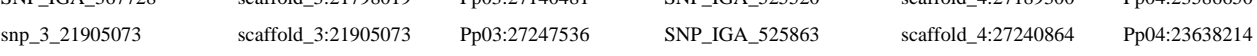

SNP_IGA_913769 Scaffold_13:560511 $\quad$ Pp03:12526639 
Supplementary Table 3 (continued)

\begin{tabular}{|c|c|c|c|c|c|c|c|c|}
\hline Scaffold 5 & Peach v1 & Peach v2 & Scaffold 6 & Peach v1 & Peach v2 & Scaffold 7 & Peach v1 & Peach v2 \\
\hline SNP_IGA_543368 & scaffold_5:302944 & Рp05:302946 & SNP_IGA_614024 & scaffold_6:3207977 & Рp06:2000736 & SNP_IGA_718070 & scaffold_7:2531116 & Рp07:2304002 \\
\hline SNP_IGA_544495 & scaffold_5:610568 & Рp05:610569 & SNP_IGA_6616119 & scaffold_6:3792224 & Рp06:1417402 & SNP_IGA_718436 & scaffold_7:2605985 & Рр07:2229107 \\
\hline SNP_IGA_544961 & scaffold_5:698214 & Pp05:698215 & SNP_IGA_640430 & scaffold_6:11288052 & Pp06:11302830 & SNP_IGA_719800 & scaffold_7:2867252 & Рр07:1967839 \\
\hline SNP_IGA_548597 & scaffold_5:1518380 & Pp05:1518366 & SNP_IGA_656551 & scaffold_6:14806613 & Pp06:16672871 & SNP_IGA_722575 & scaffold_7:3449144 & Pр07:1386205 \\
\hline SNP_IGA_553456 & scaffold_5:2477325 & Pp05:2477309 & SNP_IGA_660044 & scaffold_6:15385770 & Pp06:17252030 & SNP_IGA_723701 & scaffold_7:3679697 & Pp07:1156552 \\
\hline SNP_IGA_555093 & scaffold_5:2962847 & Pp05:2962831 & SNP_IGA_663541 & scaffold_6:16185826 & Pp06:18052094 & SNP_IGA_725456 & scaffold_7:4319294 & Рр07:515531 \\
\hline SNP_IGA_556507 & scaffold_5:3280480 & Рp05:3280731 & SNP_IGA_664903 & scaffold_6:16618275 & Pp06:18484543 & SNP_IGA_725827 & scaffold_7:4431425 & Рp07:403402 \\
\hline SNP_IGA_559057 & scaffold_5:3731230 & Рp05:3731800 & SNP_IGA_668442 & scaffold_6:18064690 & Рp06:19930779 & SNP_IGA_769194 & scaffold_7:12557752 & Рр07:12156489 \\
\hline SNP_IGA_572589 & scaffold_5:5811983 & Pp05:5813029 & SNP_IGA_669440 & scaffold_6:18064690 & Pр06:20179491 & SNP_IGA_769572 & scaffold_7:12650182 & Рр07:12248919 \\
\hline SNP_IGA_585182 & scaffold_5:9212543 & Pp05:9213434 & SNP_IGA_670727 & scaffold_6:18664554 & Pp06:20528913 & SNP_IGA_787282 & scaffold_7:19662720 & Рр07:19261236 \\
\hline SNP_IGA_586202 & scaffold_5:9505270 & Рp05:9506161 & SNP_IGA_672482 & scaffold_6:19231727 & Pр06:21096087 & SNP_IGA_787715 & scaffold_7:19780789 & Рp07:19379306 \\
\hline SNP_IGA_586935 & scaffold_5:9743759 & Рp05:9742162 & SNP_IGA_676663 & scaffold_6:20667470 & Pр06:22531824 & SNP_IGA_790469 & scaffold_7:20920976 & Рр07:20519494 \\
\hline SNP_IGA_587238 & scaffold_5:9843120 & Pp05:9841523 & SNP_IGA_678681 & scaffold_6:21455421 & Pр06:23319779 & SNP_IGA_792776 & scaffold_7:22589975 & Рр07:22188387 \\
\hline SNP_IGA_587708 & scaffold_5:9984769 & Рp05:9983173 & SNP_IGA_679038 & scaffold_6:21583109 & Рp06:23447467 & & & \\
\hline SNP_IGA_588866 & scaffold_5:10385263 & Pp05:10383553 & SNP_IGA_680310 & scaffold_6:22132364 & Pр06:23996532 & & & \\
\hline SNP_IGA_589371 & scaffold_5:10559273 & Pp05:10557562 & SNP_IGA_682254 & scaffold_6:22647696 & Рp06:24511760 & & & \\
\hline SNP_IGA_595212 & scaffold_5:12814968 & Pp05:12809737 & SNP_IGA_686073 & scaffold_6:23719823 & Pр06:25584106 & & & \\
\hline SNP_IGA_597937 & scaffold_5:13898935 & Pр05:13893708 & SNP_IGA_686138 & scaffold_6:23734168 & Pр06:25598451 & & & \\
\hline SNP_IGA_598137 & scaffold_5:13971069 & Pp05:13965842 & SNP_IGA_686657 & scaffold_6:23922965 & Pp06:25787248 & & & \\
\hline SNP_IGA_598551 & scaffold_5:14088605 & Pp05:14083378 & SNP_IGA_687855 & scaffold_6:24177743 & Pp06:26042026 & & & \\
\hline \multirow[t]{16}{*}{ SNP_IGA_598578 } & scaffold_5:14100903 & Pp05:14095676 & SNP_IGA_688290 & scaffold_6:24361336 & Pp06:26225619 & & & \\
\hline & & & SNP_IGA_688317 & scaffold_6:24366460 & Рp06:26230743 & & & \\
\hline & & & SNP_IGA_688643 & scaffold_6:24495830 & Pp06:26360114 & & & \\
\hline & & & SNP_IGA_688827 & scaffold_6:24629506 & Pp06:26493790 & & & \\
\hline & & & SNP_IGA_689681 & scaffold_6:24847752 & Pp06:26712037 & & & \\
\hline & & & SNP_IGA_691196 & scaffold_6:25176727 & Pp06:27041352 & & & \\
\hline & & & SNP_IGA_691341 & scaffold_6:25224983 & Pp06:27089604 & & & \\
\hline & & & snp_scaffold_6_25697700 & scaffold_6:25697700 & Pp06:27562320 & & & \\
\hline & & & SNP_IGA_693205 & scaffold_6:25725352 & Pp06:27589956 & & & \\
\hline & & & SNP_IGA_694098 & scaffold_6:26090466 & Рp06:27955072 & & & \\
\hline & & & SNP_IGA_695629 & scaffold_6:26491953 & Рp06:28356561 & & & \\
\hline & & & SNP_IGA_695974 & scaffold_6:26549830 & Рp06:28414438 & & & \\
\hline & & & SNP_IGA_696453 & scaffold_6:26660505 & Рp06:28525113 & & & \\
\hline & & & SNP_IGA_697735 & scaffold_6:27016342 & Рp06:28880950 & & & \\
\hline & & & SNP_IGA_698117 & scaffold_6:27083444 & Pp06:28948052 & & & \\
\hline & & & SNP_IGA_699809 & scaffold_6:27830167 & Рp06:29694774 & & & \\
\hline
\end{tabular}

\begin{tabular}{|c|c|c|}
\hline Scaffold 8 & Peach v1 & Peach v2 \\
\hline SNP_IGA_794966 & scaffold_8:642747 & Рp08:642666 \\
\hline SNP_IGA_835981 & scaffold_8:7614568 & Рp08:10502545 \\
\hline SNP_IGA_838223 & scaffold_8:8196773 & Рp08:9920158 \\
\hline SNP_IGA_841298 & scaffold_8:8555314 & Рp08:9561732 \\
\hline SNP_IGA_853053 & scaffold_8:1040172 & Рp08:11146221 \\
\hline SNP_IGA_862321 & scaffold_8:13204775 & Рp08:13949281 \\
\hline SNP_IGA_863130 & scaffold_8:13401103 & Рp08:14145609 \\
\hline SNP_IGA_864110 & scaffold_8:13728163 & Рp08:14472670 \\
\hline SNP_IGA_866829 & scaffold_8:14559613 & Рp08:15304115 \\
\hline SNP_IGA_867575 & scaffold_8:14856769 & Рp08:15601270 \\
\hline SNP_IGA_867794 & scaffold_8:14928943 & Рp08:15673444 \\
\hline SNP_IGA_669487 & scaffold_8:15387696 & Pp08:16132196 \\
\hline SNP_IGA_870010 & scaffold_8:15538262 & Рp08:16282763 \\
\hline SNP_IGA_876511 & scaffold_8:17429074 & Рp08:18173532 \\
\hline SNP_IGA_876610 & scaffold_8:17467662 & Рp08:18212120 \\
\hline SNP_IGA_876618 & scaffold_8:17469436 & Рp08:18213894 \\
\hline SNP_IGA_877141 & scaffold_8:17587403 & Рp08:18331861 \\
\hline SNP_IGA_877370 & scaffold_8:17727387 & Рp08:18471843 \\
\hline SNP_IGA_877683 & scaffold_8:17823461 & Рp08:18567917 \\
\hline SNP_IGA_878717 & scaffold_8:18085149 & Рp08:18829606 \\
\hline snp_scaffold_8_18584856 & scaffold_8:18584856 & Рp08:19329311 \\
\hline SNP_IGA_879944 & scaffold_8:18626022 & Рр08:19370477 \\
\hline SNP_IGA_879992 & scaffold_8:18640954 & Рp08:19385409 \\
\hline SNP_IGA_880355 & scaffold_8:18762779 & Рp08:19507234 \\
\hline SNP_IGA_880499 & scaffold_8:18802717 & Рp08:19547172 \\
\hline SNP_IGA_880572 & scaffold_8:18851122 & Рр08:19595577 \\
\hline SNP_IGA_881541 & scaffold_8:19095898 & Рр08:19840354 \\
\hline SNP_IGA_881593 & scaffold_8:19108751 & Рp08:19853207 \\
\hline SNP_IGA_883191 & scaffold_8:19733954 & Рp08:20478408 \\
\hline SNP_IGA_883292 & scaffold_8:19926659 & Рp08:20671113 \\
\hline SNP_IGA_883524 & scaffold_8:20088710 & Рp08:20833164 \\
\hline SNP_IGA_884538 & scaffold_8:20597072 & Рp08:21341296 \\
\hline SNP_IGA_884657 & scaffold_8:20661785 & Pp08:21406010 \\
\hline & 8:21203991 _ _ & Pp08:2194821s \\
\hline
\end{tabular}


Supplementary Table 4. QTLs found for agronomic and fruit quality traits detected in the 'Venus' $\mathrm{x}$ 'Big Top' progeny.

Trait, OTL name and OTL code, position, LOD score, Treshold, Genetic variance and effects of the OTLs detected, and position of the nearest SNP marker. Genetic Variance (VG)= Fraction of the total variation explained by the OTL, a= Additive effect. expressed as the effect of substituting an A allele by B in the AA genotype. Dist= marker position on the genetic linkage map. Abbreviations: RAC=Relative Antioxidant Capacity, RI=Ripening Index, SSC=Soluble Solids Concentration, TA=Titratable Acidity. See Table 1 for units.

\begin{tabular}{|c|c|c|c|c|c|c|c|c|c|c|c|}
\hline Trait & QTL name & QTL code & $\begin{array}{l}\text { Pos } \\
\text { cM }\end{array}$ & $\begin{array}{l}\text { LOD } \\
\text { score }\end{array}$ & Threshold & $\begin{array}{c}\text { Genetic Variance } \\
\text { VG \% }\end{array}$ & $\begin{array}{c}\text { Geno. } \\
\text { AA }\end{array}$ & $\begin{array}{c}\text { means } \\
\text { AB }\end{array}$ & $\begin{array}{c}\text { Allele_effect } \\
\text { a }\end{array}$ & Nearest Marker & $\begin{array}{l}\text { Dist } \\
\text { cM }\end{array}$ \\
\hline \multirow[t]{3}{*}{ Production } & qPRD.V-Ch3-Mean & PRD X-b & 9 & 3.34 & 2.13 & 16.3 & 5.69 & 8.01 & 2.46 & SNP_IGA_308290 & 8.87 \\
\hline & qPRD.V-Ch8-2010 & PRD 10 & 13 & 2.90 & 2.14 & 17.0 & 0.50 & 0.75 & 0.25 & SNP_IGA_841298 & 13.19 \\
\hline & qPRD.V-Ch8-Mean & PRD X-a & 24 & 3.74 & 2.13 & 18.1 & 5.80 & 8.42 & 2.62 & SNP_IGA_862321 & 23.96 \\
\hline \multirow[t]{7}{*}{ Fruit weight } & qFW.V-Ch1_1-2010 & FW 10-c & 20 & 2.66 & 2.00 & 7.7 & 202.60 & 232.88 & 30.28 & SNP_IGA_121534 & 19.64 \\
\hline & qFW.V-Ch4-2007 & FW 07 & 60 & 3.97 & 2.10 & 22.1 & 149.50 & 188.71 & 39.21 & SNP_IGA_525520 & 59.11 \\
\hline & qFW.V-Ch4-2009 & FW 09 & 46 & 7.54 & 2.08 & 34.9 & 155.92 & 198.45 & 42.53 & SNP_IGA_408981 & 45.50 \\
\hline & qFW.V-Ch4-2010 & FW 10-a & 47 & 17.97 & 2.00 & 50.1 & 186.05 & 254.20 & 68.15 & SNP_IGA_408981 & 45.50 \\
\hline & qFW.V-Ch4-Mean & FW X-a & 46 & 17.38 & 2.13 & 54.7 & 165.41 & 214.91 & 49.50 & SNP_IGA_408981 & 45.50 \\
\hline & qFW.BT-Ch8-2010 & FW 10-b & 25 & 3.45 & 2.19 & 19.9 & 192.91 & 233.72 & 40.81 & SNP_IGA_835981 & 31.76 \\
\hline & qFW.BT-Ch8-Mean & FW X-b & 9 & 3.07 & 2.21 & 15.3 & 177.97 & 206.87 & 28.90 & ВРРС̄ $03 \overline{3}$ & 0.00 \\
\hline \multirow[t]{6}{*}{ Firmness } & qFF.V-Ch4-2007 & FIR 07 & 48 & 8.37 & 2.33 & 43.2 & 26.59 & 39.54 & 12.95 & SNP_IGA_408981 & 45.50 \\
\hline & qFF.V-Ch4-2009 & FIR 09-a & 55 & 3.37 & 2.12 & 19.5 & 41.62 & 47.51 & 5.89 & SNP_IGA_440110 & 54.65 \\
\hline & qFF.V-Ch4-Mean & FIR X-a & 54 & 8.70 & 2.15 & 37.2 & 38.13 & 44.72 & 6.59 & SNP_IGA_440110 & 54.65 \\
\hline & qFF.BT-Ch5-2009 & FIR 09-b & 12 & 4.74 & 2.21 & 24.9 & 40.45 & 47.01 & 6.56 & SNP_IGA_555093 & 11.90 \\
\hline & qFF.BT-Ch5-2010 & FIR 10 & 3 & 3.42 & 2.17 & 19.9 & 43.15 & 47.61 & 4.47 & SNP_IGA_544961 & 2.94 \\
\hline & qFF.BT-Ch5-Mean & FIR X-b & 12 & 2.27 & 2.23 & 14.6 & 38.64 & 42.65 & 4.01 & SNP_IGA_585182 & 35.73 \\
\hline \multirow[t]{10}{*}{$\mathrm{SSC}$} & qSSC.V-Ch2_2-2009 & SSC 09-d & 0 & 2.52 & 2.15 & 10.7 & 12.94 & 14.28 & 1.34 & SNP_IGA_140938 & 0.00 \\
\hline & qSSC.V-Ch4-2007a & SSC 07-a & 29 & 3.45 & 2.06 & 18.5 & 13.14 & 12.85 & -0.29 & SNP_IGA_399337 & 29.19 \\
\hline & qSSC.V-Ch4-2007b & SSC 07-b & 44 & 5.29 & 2.06 & 28.0 & 12.63 & 13.62 & 0.99 & SNP_IGA_407115 & 44.03 \\
\hline & qSSC.V-Ch4-2009a & SSC 09-a & 32 & 2.61 & 2.15 & 11.3 & 13.42 & 13.72 & 0.30 & SNP_IGA_400572 & 32.13 \\
\hline & qSSC.V-Ch4-2009b & SSC 09-b & 44 & 6.49 & 2.15 & 27.6 & 12.89 & 14.45 & 1.57 & SNP_IGA_407115 & 44.03 \\
\hline & qSSC.V-Ch4-2010 & SSC $10-\mathrm{a}$ & 54 & 3.85 & 2.10 & 21.4 & 12.73 & 14.51 & 1.78 & SNP_IGA_440110 & 54.65 \\
\hline & qSSC.V-Ch4-Mean & SSC X-a & 44 & 4.02 & 2.20 & 22.0 & 12.85 & 14.22 & 1.37 & SNP_IGA_407115 & 44.03 \\
\hline & qSSC.BT-Ch5-2009 & SSC 09-c & 21 & 3.02 & 2.23 & 17.1 & 12.70 & 14.18 & 1.48 & SNP_IGA_572589 & 24.39 \\
\hline & qSSC.BT-Ch5-2010 & SSC $10-b$ & 33 & 2.60 & 2.14 & 15.2 & 12.80 & 13.98 & 1.18 & SNP IGA 585182 & 35.73 \\
\hline & qSSC.BT-Ch5-Mean & SSC X-b & 29 & 2.32 & 2.18 & 13.5 & 12.82 & 13.86 & 1.04 & SNP_IGA_572589 & 24.39 \\
\hline
\end{tabular}


Supplementary Table 4. (Continued)

\begin{tabular}{|c|c|c|c|c|c|c|c|c|c|c|c|}
\hline Trait & QTL name & QTL code & $\begin{array}{l}\text { Pos } \\
\text { cM }\end{array}$ & $\begin{array}{l}\text { LOD } \\
\text { score }\end{array}$ & Threshold & $\begin{array}{c}\text { Genetic Variance } \\
\text { VG \% }\end{array}$ & $\begin{array}{c}\text { Geno. } \\
\text { AA }\end{array}$ & $\begin{array}{c}\text { means } \\
\mathrm{AB}\end{array}$ & $\begin{array}{c}\text { Allele_effect } \\
\text { a }\end{array}$ & Nearest Marker & $\begin{array}{l}\text { Dist } \\
\text { cM }\end{array}$ \\
\hline \multirow[t]{4}{*}{$\mathrm{pH}$} & qpH.BT-Ch5-2007 & pH 07 & 4 & 15.17 & 2.36 & 52.2 & 3.36 & 3.75 & 0.40 & SNP_IGA_544961 & 2.94 \\
\hline & qpH.BT-Ch5-2009 & pH 09 & 3 & 27.96 & 2.48 & 85.3 & 3.52 & 4.10 & 0.58 & SNP_IGA_544961 & 2.94 \\
\hline & qpH.BT-Ch5-2010 & $\mathrm{pH} 10$ & 4 & 21.42 & 2.55 & 75.7 & 3.27 & 3.80 & 0.53 & SNP_IGA_5444961 & 2.94 \\
\hline & qpH.BT-Ch5-Mean & $\mathrm{pH} \mathrm{X}$ & 3 & 26.66 & 2.62 & 84.0 & 3.35 & 3.86 & 0.51 & SNP_IGA_544961 & 2.94 \\
\hline \multirow[t]{4}{*}{ TA } & qTA.BT-Ch5-2007 & TA $07-a$ & 3 & 12.67 & 2.63 & 60.4 & 0.57 & 1.00 & 0.43 & SNP_IGA_544961 & 2.94 \\
\hline & qTA.BT-Ch5-2009 & TA 09 & 3 & 25.4 & 2.56 & 82.5 & 0.80 & 0.42 & -0.37 & SNP_IGA_544961 & 2.94 \\
\hline & qTA.BT-Ch5-2010 & TA 10 & 2 & 14.8 & 2.54 & 62.6 & 1.02 & 0.44 & -0.59 & SNP_IGA_544961 & 2.94 \\
\hline & qTA.BT-Ch5-Mean & TA X & 3 & 27.63 & 2.53 & 84.6 & 0.81 & 0.35 & -0.46 & SNP_IGA_544961 & 2.94 \\
\hline \multirow[t]{4}{*}{ RI (SSC/TA) } & qRI.BT-Ch5-2007 & RI 07 & 0 & 7.55 & 2.45 & 42.4 & 14.72 & 29.29 & 14.57 & SNP_IGA_543368 & 0.00 \\
\hline & qRI.BT-Ch5-2009 & RI 09 & 3 & 17.41 & 2.56 & 69.8 & 16.67 & 33.72 & 17.06 & SNP_IGA_544961 & 2.94 \\
\hline & qRI.BT-Ch5-2010 & RI 10 & 4 & 11.38 & 2.54 & 53.1 & 15.28 & 34.86 & 19.58 & SNP_IGA_548597 & 5.93 \\
\hline & qRI.BT-Ch5-Mean & RI X & 3 & 21.55 & 2.51 & 76.8 & 15.41 & 32.78 & 17.52 & SNP_IGA_544961 & 2.94 \\
\hline \multirow[t]{4}{*}{ Total sugars } & qTSU.V-Ch2_2-2009 & TSU 09-b & 0 & 2.52 & 2.14 & 15.5 & 84.98 & 96.64 & 11.66 & SNP_IGA_140938 & 0.00 \\
\hline & qTSU.BT-Ch4-2010 & TSU 10 & 34 & 2.20 & 2.05 & 14.9 & 82.48 & 97.68 & 15.20 & SNP_IGA_477941 & 33.97 \\
\hline & qTSU.BT-Ch5-2009 & TSU 09-c & 19 & 3.15 & 2.23 & 16.6 & 83.37 & 95.38 & 12.01 & SNP_IGA_559057 & 14.84 \\
\hline & qTSU.BT-Ch5-Mean & TSU X-c & 23 & 2.43 & 2.01 & 15.1 & 81.30 & 91.40 & 10.10 & SNP_IGA_572589 & 24.39 \\
\hline \multirow[t]{4}{*}{ Sucrose } & qSUC.V-Ch4-2010 & SUC 10 & 11 & 2.37 & 2.13 & 18.9 & 62.77 & 51.04 & -11.73 & SNP_IGA_378159 & 11.02 \\
\hline & qSUC.BT-Ch5-2007 & SUC 07 & 5 & 2.87 & 2.16 & 18.6 & 60.85 & 47.99 & -12.86 & SNP_IGA_548597 & 5.93 \\
\hline & qSUC.BT-Ch5-2009 & SUC 09 & 17 & 4.21 & 2.19 & 22.0 & 54.03 & 64.79 & 10.89 & SNP_IGA_559057 & 14.84 \\
\hline & qSUC.BT-Ch5-Mean & SUC X & 3 & 6.14 & 2.13 & 30.4 & 50.84 & 61.45 & 10.61 & SNP_IGA_544961 & 2.94 \\
\hline Glucose & qGLU.V-Ch4-2007 & GLU 07 & 48 & 4.07 & 2.06 & 23.8 & 9.18 & 11.51 & 2.33 & SNP_IGA_408981 & 45.50 \\
\hline \multirow[t]{6}{*}{ Sorbitol } & qSOR.V-Ch4-2007 & SOR 07 & 46 & 12.88 & 2.14 & 51.2 & 3.15 & 7.65 & 4.50 & SNP_IGA_408981 & 45.50 \\
\hline & qSOR.V-Ch4-2008 & SOR 08 & 49 & 5.75 & 2.02 & 27.3 & 3.92 & 8,27 & 4.35 & SNP_IGA_437516 & 51.66 \\
\hline & qSOR.V-Ch4-2009 & SOR 09 & 46 & 18.59 & 2.27 & 57.7 & 4.06 & 10.54 & 6.48 & SNP_IGA_408981 & 45.50 \\
\hline & qSOR.V-Ch4-2010 & SOR 10a & 54 & 5.62 & 2.16 & 36.8 & 5.32 & 9.14 & 3.82 & SNP_IGA_440110 & 54.65 \\
\hline & qSOR.V-Ch4- Mean & SOR X & 47 & 22.22 & 2.12 & 60.5 & 3.96 & 8.66 & 4.71 & SNP_IGA_408981 & 45.50 \\
\hline & qSOR.BT-Ch5-2010 & SOR $10 b$ & 40 & 2.56 & 2.16 & 20.5 & 4.60 & 7.32 & 2.72 & SNP_IGA586202 & 40.28 \\
\hline
\end{tabular}


Supplementary Table 4. (Continued)

\begin{tabular}{|c|c|c|c|c|c|c|c|c|c|c|c|}
\hline Trait & QTL name & QTL code & $\begin{array}{l}\text { Pos } \\
\text { cM }\end{array}$ & $\begin{array}{l}\text { LOD } \\
\text { score }\end{array}$ & Threshold & $\begin{array}{c}\text { Genetic Variance } \\
\text { VG \% }\end{array}$ & $\begin{array}{c}\text { Geno. } \\
\text { AA }\end{array}$ & $\begin{array}{c}\text { means } \\
\mathrm{AB}\end{array}$ & $\begin{array}{c}\text { Allele_effect } \\
\text { a }\end{array}$ & Nearest Marker & $\begin{array}{l}\text { Dist } \\
\text { cM }\end{array}$ \\
\hline \multirow[t]{5}{*}{ Fructose } & qFRU.V-Ch2_1-2008 & FRU 08-a & 3 & 2.90 & 2.00 & 13.2 & 14.67 & 12.54 & -2.13 & SNP_IGA_249849 & 2.98 \\
\hline & qFRU.V-Ch4-2007 & FRU 07-a & 48 & 2.73 & 2.14 & 17.6 & 9.95 & 11.75 & 1.80 & SNP_IGA_408981 & 45.50 \\
\hline & qFRU.BT-Ch1_2-2008 & FRU 08-b & 23 & 2.62 & 2.21 & 16.5 & 12.54 & 14.21 & 2.27 & SNP_IGA_25403 & 23.04 \\
\hline & qFRU.BT-Ch1_2-Mean & FRU X-b & 23 & 2.48 & 2.26 & 15.9 & 11.47 & 12.88 & 1.41 & SNP_IGA_25403 & 23.04 \\
\hline & qFRU.BT-Ch5-2007 & FRU 07-b & 54 & 3.57 & 2.28 & 22.7 & 9.71 & 11.75 & 2.03 & SNP_IGA_595212 & 53.74 \\
\hline \multirow[t]{3}{*}{ Total Phenolics } & qPHE.V-Ch2_2-2009 & PHE 09-a & 0 & 2.32 & 2.16 & 14.3 & 19.37 & 23.55 & 4.18 & SNP_IGA_140938 & 0.00 \\
\hline & qPHE.V-Ch4-Mean & PHE X & 45 & 2.67 & 2.18 & 15.8 & 30.66 & 35.37 & 4.71 & SNP_IGA_408981 & 45.50 \\
\hline & qPHE.BT-Ch2-2009 & PHE 09-b & 1 & 2.50 & 2.21 & 15.0 & 23.55 & 19.37 & -4.18 & SNP_IGA_141612 & 1.47 \\
\hline \multirow[t]{5}{*}{ Flavonoids } & qFLV.V-Ch2_2-2010 & FLV 10-a & 1.5 & 2.76 & 1.82 & 17.0 & 6.31 & 10.91 & 4.59 & SNP_IGA_185060 & 1.47 \\
\hline & qFLV.V-Ch3-2008 & FLV 08-c & 3 & 2.18 & 2.02 & 10.1 & 24.23 & 19.26 & -4.97 & SNP_IGA_298154 & 2.98 \\
\hline & qFLV.V-Ch4-2008 & FLV 08-a & 53 & 4.40 & 2.02 & 17.8 & 18.81 & 26.03 & 7.22 & SNP_IGA_437516 & 51.66 \\
\hline & qFLV.V-Ch7-2008 & FLV 08-b & 0 & 4.04 & 2.02 & 18.6 & 24.84 & 17.38 & -7.45 & SNP_IGA_787282 & 0.00 \\
\hline & qFLV.BT-Ch2-2010 & FLV 10-b & 0 & 2.86 & 1.93 & 17.1 & 10.91 & 6.31 & -4.59 & SNP_IGA_161939 & 0.00 \\
\hline \multirow[t]{3}{*}{ Anthocyanins } & qANT.BT-Ch5-2009 & ANT 09 & 3 & 3.24 & 1.93 & 18.7 & 6.45 & 2.61 & -3.84 & SNP_IGA_544961 & 2.94 \\
\hline & qANT.BT-Ch5-2010 & ANT 10 & 3 & 5.28 & 2.19 & 27.6 & 7.03 & 2.88 & -4.15 & SNP_IGA_544961 & 2.94 \\
\hline & qANT.BT-Ch5-Mean & ANT X & 3 & 6.02 & 2.14 & 30.0 & 2.29 & 4.27 & 1.98 & SNP_IGA_544961 & 2.94 \\
\hline \multirow[t]{3}{*}{ RAC } & qRAC.V-Ch4-2009 & RAC 09-a & 46 & 7.47 & 2.14 & 34.9 & 274.23 & 391.40 & 117.17 & SNP_IGA_408981 & 45.50 \\
\hline & qRAC.V-Ch4-Mean & RAC X & 54 & 3.58 & 2.03 & 20.2 & 415.58 & 498.13 & 82.55 & SNP_IGA_440110 & 54.65 \\
\hline & qRAC.BT-Ch8-2009 & RAC 09-b & 82 & 2.72 & 2.28 & 9.3 & 358.26 & 298.65 & -59.61 & SNP_IGA_884538 & 81.39 \\
\hline
\end{tabular}

